\title{
APOE4 enhances age-dependent decline in cognitive function by down-regulating an NMDA receptor pathway in EFAD-Tg mice
}

De-shan Liu ${ }^{2,3 \dagger}$, Xiao-dong Pan ${ }^{1,2,3 \dagger}$, Jing Zhang ${ }^{2,3}$, Hui Shen², Nicole C Collins ${ }^{4}$, Arron M Cole ${ }^{4}$, Kevin P Koster ${ }^{4}$, Manel Ben Aissa ${ }^{4}$, Xiao-man Dai ${ }^{2,3}$, Meng Zhou ${ }^{4}$, Leon M Tai ${ }^{4}$, Yuan-gui Zhu ${ }^{2,3}$, Mary Jo LaDu ${ }^{4^{*}}$ and Xiao-chun Chen ${ }^{1,2,3^{*}}$

\begin{abstract}
Background: Alzheimer's disease (AD) causes progressive loss of memory and cognition, exacerbated by APOE4, the greatest genetic risk factor for AD. One proposed mechanism for apolipoprotein $E$ (apoE) effects on cognition is via NMDAR-dependent signaling. APOE genotype-specific effects on this pathway were dissected using EFAD-transgenic (Tg) mice (5xFAD mice, that over-express human amyloid-beta (Aß) via 5 familial-AD (FAD) mutations, and express human apoE), and 5xFAD/APOE-knockout (KO) mice. Previous data from EFAD-Tg mice demonstrate age-dependent (2-6 months), apoE-specific effects on the development of A $\beta$ pathology. This study tests the hypothesis that apoE4 impairs cognition via modulation of NMDAR-dependent signaling, specifically via a loss of function by comparison of E4FAD mice with 5XFAD/APOE-KO mice, E3FAD and E2FAD mice.

Results: Using female E2FAD, E3FAD, E4FAD and 5xFAD/APOE-KO mice aged 2-, 4-, and 6-months, the Y-maze and Morris water maze behavioral tests were combined with synaptic protein levels as markers of synaptic viability. The results demonstrate a greater age-induced deficit in cognition and reduction in PSD95, drebrin and NMDAR subunits in the E4FAD and 5xFAD/APOE-KO mice compared with E2FAD and E3FAD mice, consistent with an apoE4 loss of function. Interestingly, for NMDAR-mediated signaling, the levels of p-CaMK-Il followed this same apoE-specific pattern as cognition, while the levels of $p-C R E B$ and BDNF demonstrate an apoE4 toxic gain of function: E2FAD > E3FAD > 5XFAD/APOE-KO > E4FAD.

Conclusion: These findings suggest that compared with E2FAD and E3FAD, E4FAD and 5xFAD/APOE-KO mice exhibit enhanced age-induced reductions in cognition and key synaptic proteins via down-regulation of an NMDAR signaling pathway, consistent with an apoE4 loss of function. However, levels of p-CREB and BDNF, signaling factors common to multiple pathways, suggest a gain of toxic function. Publications in this field present contradictory results as to whether APOE4 imparts a loss or gain of function. As with the results reported herein, the overall effect of APOE4 on a given CNS-specific measure will be the product of multiple overlapping mechanisms. Thus, caution remains critical in determining whether APOE gene inactivation or therapies that correct the loss of positive function related to apoE4, are the appropriate therapeutic response.
\end{abstract}

Keywords: Alzheimer's disease, Apolipoprotein E, Behavior, Synaptic proteins, Signaling pathways, Transgenic mice

\footnotetext{
* Correspondence: mladu@uic.edu; chenxc998@163.com

${ }^{\dagger}$ Equal contributors

${ }^{4}$ Department of Anatomy and Cell Biology, University of Illinois at Chicago,

808 S.Wood St., M/C 512, 60612 Chicago, IL, USA

1 Department of Neurology, Fujian Medical University Union Hospital, 29

Xinquan Road, 350001 Fuzhou, China

Full list of author information is available at the end of the article
}

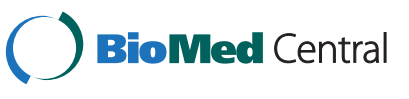

(C) 2015 Liu et al.; licensee BioMed Central. This is an Open Access article distributed under the terms of the Creative Commons Attribution License (http://creativecommons.org/licenses/by/4.0), which permits unrestricted use, distribution, and reproduction in any medium, provided the original work is properly credited. The Creative Commons Public Domain Dedication waiver (http://creativecommons.org/publicdomain/zero/1.0/) applies to the data made available in this article, unless otherwise stated. 


\section{Introduction}

Alzheimer's disease (AD) is a progressive neurodegenerative disease that causes loss of memory and cognitive function, and is the most common cause of dementia in individuals over the age of $60 . A P O E 4$, the greatest genetic risk factor for sporadic Alzheimer's disease (AD), increases risk $\sim 3$ - and 15-fold with a single or double allele [1-11] compared to APOE3, whereas APOE2 decreases AD risk $\sim 2$-fold per allele [12-16]. The multifactorial mechanisms through which apolipoprotein $\mathrm{E}$ (apoE) affects $\mathrm{AD}$ risk ultimately converge on modulation of cognitive function. As well, the amyloid- $\beta$ peptide (A $\beta$ ) [17-19], the proposed proximal neurotoxin in $A D$, is a major cause of impaired synaptic function, particularly soluble oligomeric forms of the peptide (oA $\beta)$ [20-23]. However, how human (h)-apoE interacts with $A \beta$ to affect cognitive function, and the potential underlying neuronal signaling pathways, remains unclear, in part due to the lack of a tractable familial AD (FAD)-Tg mouse model. In addition, debate continues on whether apoE4 represents an overall loss of positive function or gain of toxic function, a distinction that significantly impacts therapeutic approaches for targeting not only $A P O E 4$-induced $\mathrm{AD}$ risk, but for the effects on all h$A P O E$ genotypes.

In $\mathrm{AD}$ patients, $A P O E 4$ is associated with an earlier age of onset for cognitive deficits than APOE3 [6-11], and possibly a faster rate of cognitive decline [24,25], though results are conflicting regarding the latter. However, even in the absence of $\mathrm{AD}$, older APOE4 carriers $(60+$ years of age) exhibit deficits in episodic memory and higher rates of cognitive decline compared to APOE3 carriers [26-29]. Although these data demonstrate greater apoE4-induced cognitive impairment compared to apoE3, it remains unclear whether this is a loss of positive function or gain of toxic function. This issue is highlighted by a recent case report of a 40-year-old male patient with an ablative frame shift mutation that results in a complete lack of apoE [30]. The patient is described as cognitively normal on gross functional tests (MMSE), raising the hypothesis that all the h- $A P O E$ genotypes are either a gain of toxic function, or are not required for cognitive function. However, sub-domain tests indicate deficits in memory, language, visual-spatial abilities and executive function, in addition to signs of dyslexia [30], supporting the loss of function hypothesis. Data from $\mathrm{Tg}$ mouse models on the role of apoE on cognitive decline are primarily derived from models that express h-apoE, but without h-A $\beta$ pathology. As with non-AD patients, in APOE-TR mice, apoE4 is associated with cognitive deficits in both young (Morris water maze, Barnes maze) [31,32] and older mice (Morris water maze, Y-maze) [33,34]. Similar data were also observed in mice expressing h-apoE under the control of heterologous promoters (reviewed [35]). In FAD-Tg mouse models expressing h-apoE under the control of the NSE promoter, behavioral performances (water maze) follow the pattern apoE3 $>$ apoE4 $=$ apoE-knockout $(\mathrm{KO})$, consistent with a loss of positive function for apoE4 [36]. However, as apoE is physiologically expressed by glia, the relevance of these data is unclear.

At the synaptic level, AD patients exhibit decreased levels of postsynaptic intracellular scaffold proteins, including postsynaptic density protein 95 (PSD95) and drebrin, suggesting post-synaptic disruption precedes loss of pre-synaptic proteins to initiate the cognitive deficits characteristic of the disease (reviewed in [37-39]). Importantly, decreased levels of PSD95 and drebrin can lead to decreased expression of $N$-methyl-D-aspartate receptor (NMDAR) subunits (N1, NR2A and NR2B) $[37,38]$. Clinically, in vivo and in vitro evidence indicate that $\mathrm{AD}, \mathrm{A} \beta$, inflammation and chronic vasculitis can result in chronic NMDAR activation, disrupting postsynaptic ionic gradients, long-term potentiation (LTP) and cognition [37-39]. Further, lower NDMA receptor levels may result in a decreased $\mathrm{Ca}^{2+}$-dependent activation of the calcium-calmodulin-II (CaMK-II)/cAMP response binding element peptide (CREB) pathway, leading to decreased production of the brain derived neurotropic factor (BDNF), critical for synaptic function and for increasing NMDAR levels via positive feedback [39-43]. Mechanistically, an apoE4-induced reduction in postsynaptic proteins may disrupt CaMK-II/CREB/BDNF signaling to impair cognitive function [44]. Similar effects are observed in long-term primary neuron-glia co-cultures, as apoE4 accelerates the loss of GluN1 levels and mature spines compared to apoE3 [45]. Further, by inducing intracellular sequestration, apoE4 reduces neuronal cell-surface expression of NMDA receptors in vitro [46]. However, little is known about the $A P O E$ genotype-specific effects on these processes in combination with $\mathrm{AD}$ pathology.

To assess whether apoE4 imparts a loss or gain of function requires a comparison to the absence of apoE (APOE-KO), not simply a comparison to apoE2/apoE3. For example, in vivo studies demonstrate that with LPSinduced inflammation and amyloid deposition, apoE4 is anti-inflammatory [47] and anti-amyloidigenic [35,48] compared to apoE-KO, though apoE3 is better than apoE4. In other data more directly related to synaptic dysfunction, no differences were observed between apoE4 and apoE-KO in measures including spine density and LTP [49,50], with apoE3 higher than both. Finally, apoE4 exhibits a gain of toxic function compared to apoE-KO for oA 342 -dependent attenuation of LTP [51] and oA 342 -induced neurotoxicity in neuron/glial cocultures [52]. Thus, it is critical to determine the effect of $\mathrm{h}$-apoE on postsynaptic protein expression and signaling in the EFAD and 5xFAD/APOE-KO mice. 
As data indicate that the APOE4-induced risk for $\mathrm{AD}$ is significantly greater in females compared to males in both humans and APOE-TR mice [35,53-55], female EFAD-Tg mice [48] were used in this study to identify the effects of $\mathrm{A} \beta$ pathology on $A P O E$ genotype-specific modulation of behavior. EFAD mice are an AD-Tg mouse model with h-apoE expressed under the regulated control of the endogenous mouse (m)-apoE promoter (APOE-TR) [56] and $\mathrm{h}-\mathrm{A} \beta 42$ over-expressed via the 5xFAD-Tg mice, an FAD-Tg mouse model [57]. In addition, E4FAD mice were compared to $5 \mathrm{xFAD} / A P O E$ $\mathrm{KO}$ to address whether apoE4 imparts a loss of positive or gain of toxic function. Finally, E2FAD, E3FAD, E4FAD and $5 \times \mathrm{xAD} / A P O E-\mathrm{KO}$ mice at 2-, 4-, and 6-months of age were used as previous data demonstrated significant agedependent (2-6 months), apoE isoform-specific (apoE4 > apoE3 = apoE2) effects on the development of $A \beta$ pathology in EFAD mice $[48,58,59]$. Therefore, from a translational perspective, it is important to incorporate sex, $A P O E$ genotype, and $\mathrm{A} \beta$ pathology in a preclinical model. Using the recently developed, tractable EFAD-Tg mice and 5XFAD/APOE-KO mice, age-dependent changes in spatial recognition memory (Y-maze and Morris water maze), pre-synaptic (synaptophysin) and post-synaptic (PSD95 and drebrin) protein levels, and the NMDAR subunits levels and activation of the CaMK-II-CREB-BDNF pathway were measured in 2-, 4- and 6-month female mice. The results demonstrate a greater age-induced deficit in behavior and reduction in postsynaptic proteins in the E4FAD and 5XFAD/APOE-KO mice compared with E2FAD and E3FAD mice, consistent with an apoE4 loss of function. However, further results demonstrate that while phosphorylated CaMK-II (p-CaMK-II) followed the same apoE-specific pattern as cognition and synaptic protein levels, levels of phosphorylated CREB (p-CREB) and BDNF demonstrate an apoE4 toxic gain of function.

\section{Results \\ Age-dependent decline in E4FAD mice in Y-maze spatial recognition memory test and deficits in E4FAD and 5xFAD/ APOE-KO mice compared to E3FAD and E2FAD mice}

To determine the effect of $A P O E$ genotype and age on cognitive function, spatial recognition memory was assessed via Y-maze in 2-, 4-, and 6-month EFAD and $5 \mathrm{xFAD} / A P O E-\mathrm{KO}$ mice. There were no significant differences in the number of arm entrances (baseline-line exploratory activity, Figure $1 \mathrm{~A}$ ) or spontaneous alternation (Figure $1 \mathrm{~B}$ ) by $A P O E$ genotype, however there was significance in both tests between age groups (two-way ANOVA, Additional file 1). Bonferroni post-hoc analysis demonstrated significantly lower arm entrances between 2 and 6 month old mice for E2FAD, E4FAD, and $5 \times \mathrm{FAD} /$ $A P O E-K O(\mathrm{p}>0.05)$ (Figure 1A). Two-way ANOVA analysis showed a significant age effect for spontaneous alternation, however Bonferroni post-hoc analysis revealed no significance (Figure 1B). Thus, subsequent effects (Figure 1C,D) were not significantly influenced by differences in spontaneous exploratory spatial navigation.

Spatial recognition memory was assessed using the natural tendency of mice to preferentially explore novel over familiar spatial environments in a two-trial Y-maze test, measuring the number of novel arms entered (Figure $1 \mathrm{C}$ ) and time spent in novel arms (Figure 1D). Two-way ANOVA demonstrated a genotype and age effect but not an age $\mathrm{X}$ genotype effect for both number of novel arms entered and time in novel arms (Additional file 1). Bonferroni post-hoc analysis revealed that a significant age effect was observed for the E4FAD mice from 2-4 months and from 2-6 months (Figure 1C,D), while E3FAD and $5 \mathrm{xFAD} / A P O E-\mathrm{KO}$ also decreased significantly form 2-6 in number of arms entered (1C). In comparisons among the genotypes at each age, E4FAD mice displayed deficits in spatial cognition (fewer novel arm entries) compared to E2FAD and E3FAD mice at 4 months, and compared to E2FAD mice at 6 months (Figure 1C), with no difference between E4FAD and 5xFAD/APOE-KO mice. Results for the time spent in the novel arms (Figure 1D) suggest that both E4FAD and 5xFAD/APOE-KO mice spent consistently less time in novel arms than E2FAD and E3FAD mice. Of interest, time in novel arms for E4FAD mice at 6 months is significantly lower than $5 \mathrm{xFAD} / A P O E-\mathrm{KO}$ mice, the only example of an apoE4 gain of toxic function for the Y-maze (Figure 1D). Together these results are consistent with E2FAD $\geq$ E3FAD $>5 \times$ FAD $/ A P O E-K O \geq$ E4FAD for spatial recognition memory as assessed by Y-maze.

Deficits in spatial and learning and memory in the Morris water maze are greater in E4FAD and 5xFAD/APOE-KO mice compared to E3FAD and E2FAD mice

Cognition was further assessed for spatial reference and working memory using the MWM (Figure 2). Two MWM tests were utilized to assess the capacity of mice to learn the location of a hidden platform using relevant visual cues. A 5-day training phase was used as a measure of spatial learning and memory, followed by removal of the platform for two probe trials (Figure 2C) to assess retrieval of spatial reference memory. All genotypes at each age exhibited comparable swimming speed and sensory motor functions, as determined by a visual cue test (data not shown). Thus, sensory motor or motivational effects on learning and memory performance were considered comparable. Swimming tracks for training and the probe trials were recorded for each day for each genotype and 2-, 4- and 6-month (representative example, Figure 2A).

For the 5-day training phase, the time to find the hidden platform was recorded and plotted against trial date at 2-, 4- and 6-month (Figure 2B). There was a genotype 


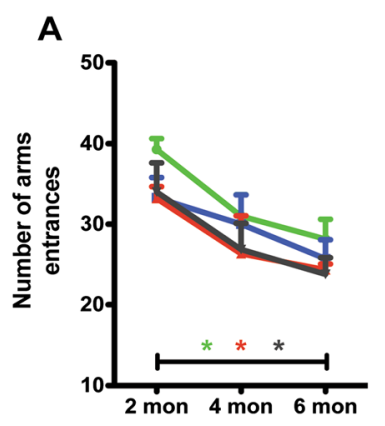

C

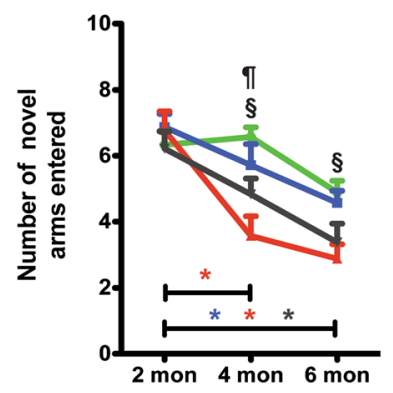

B
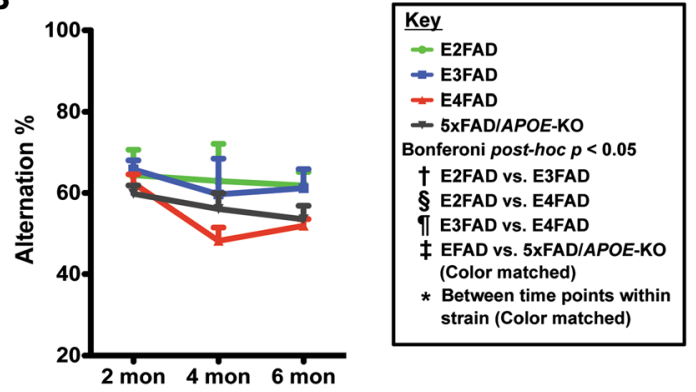

D

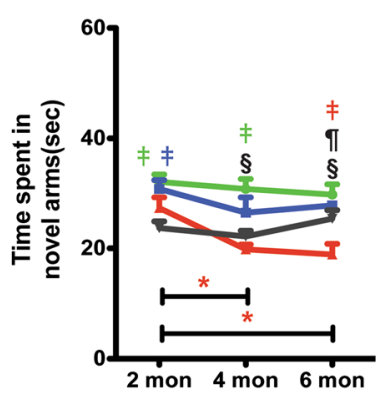

Figure 1 Age-dependent decline in Y-maze of performance in E4FAD mice compared to E3FAD and E2FAD mice. Results at 2-, 4-, and 6-months of age for E2FAD, E3FAD, E4FAD, and 5XFAD/APOE-KO mice: Y-maze results for (A) the total number of arm entries, (B) percent alternation, (C) novel arm recognition, and (D) time spent in novel arms. $N \geq 6$ per group, expressed as means \pm S.E.M. Significant differences at $p<0.05$ via two-way ANOVA, Bonferroni post-hoc test identified by: † between E2FAD and E3FAD, § between E2FAD and E4FAD, "between $\mathrm{E} 3 \mathrm{FAD}$ and E4FAD. Color matched ${ }^{\ddagger}$ (green $=\mathrm{E} 2 \mathrm{FAD}$, blue $=\mathrm{E} 3 \mathrm{FAD}$, red $=\mathrm{E} 4 \mathrm{FAD}$, grey $=5 \times \mathrm{FAD} / \mathrm{APOE}-\mathrm{KO}$ ) between EFAD strain and 5XFAD/ $A P O E-K O$. Along the $x$-axis, color matched *indicates significant differences between time points within a mouse strain. There is no significant change with age unless marked.

and training day effect for all age groups (two-way ANOVA, Additional file 1). Bonferroni post-hoc analysis revealed that for all the genotypes at each age, the time to reach the hidden platform decreased from 1 to 5 days in training phase, indicating that the mice were able to learn the task, with the exception of $5 \mathrm{xFAD} / A P O E-\mathrm{KO}$ mice at 4 months. The escape latency for the E2FAD and E3FAD mice decreased significantly from 1 to 3 days at both 4 and 6 months, while the E4FAD and $5 \mathrm{xFAD} / A P O E-\mathrm{KO}$ mice required the full 5 days for a significant learning effect at 4 and 6 months. It is also interesting to note that from 2-6 months, the escape latency, measured as the slope of the learning curve, increased from 2 to 6 months for the E4FAD $(-4.26$ to $-2,30)$ and $5 \mathrm{xFAD} / A P O E-\mathrm{KO}$ mice $(-5.13$ to -3.35$)$, suggesting failure of some compensatory effect over time. In comparisons among the genotypes at each age, the escape latency was longer for E4FAD compared to E2FAD mice at several training days for 2-, 4-, and 6-months (Figure 2B). This result suggests that on a given day, E4FAD mice showed delayed acquisition and poor retention of spatial information from the day before and, therefore, took longer to reach the position of the platform than the E2FAD mice. In general, the results for training trials of E4FAD were comparable to 5xFAD/ APOE-KO mice, while E2FAD and E3FAD mice were comparable.

After 5 days of training, the platform was removed and the number of times the mice crossed the previous platform location and the time spent in the target quadrant searching for the platform were recorded (Figure 2C). There was a genotype and age effect, but not a genotype $\mathrm{X}$ age effect, for both probe trials (two-way ANOVA, Additional file 1). Post-hoc analysis by Bonferroni revealed a significant age effect for E4FAD mice for both measures, with a similar trend for the $5 \times \mathrm{FAD} / A P O E$ KO. This decline is particularly dramatic for platform crosses at 6 months (Figure $2 \mathrm{C}$ ). In comparisons among the genotypes at each age, there were no genotype effects at 2 months in either probe trial (Figure 2C). In comparisons among the genotypes at each age, the E4FAD mice spent less time in the target quadrant than both E2FAD and E3FAD mice at 4 months, and less than E2FAD at 6 months. For the number of platform crosses, the only significant difference was between E2FAD and E4FAD mice at 6 months.

The results for the MWM indicate that recently acquired spatial learning and working memory, and long- 

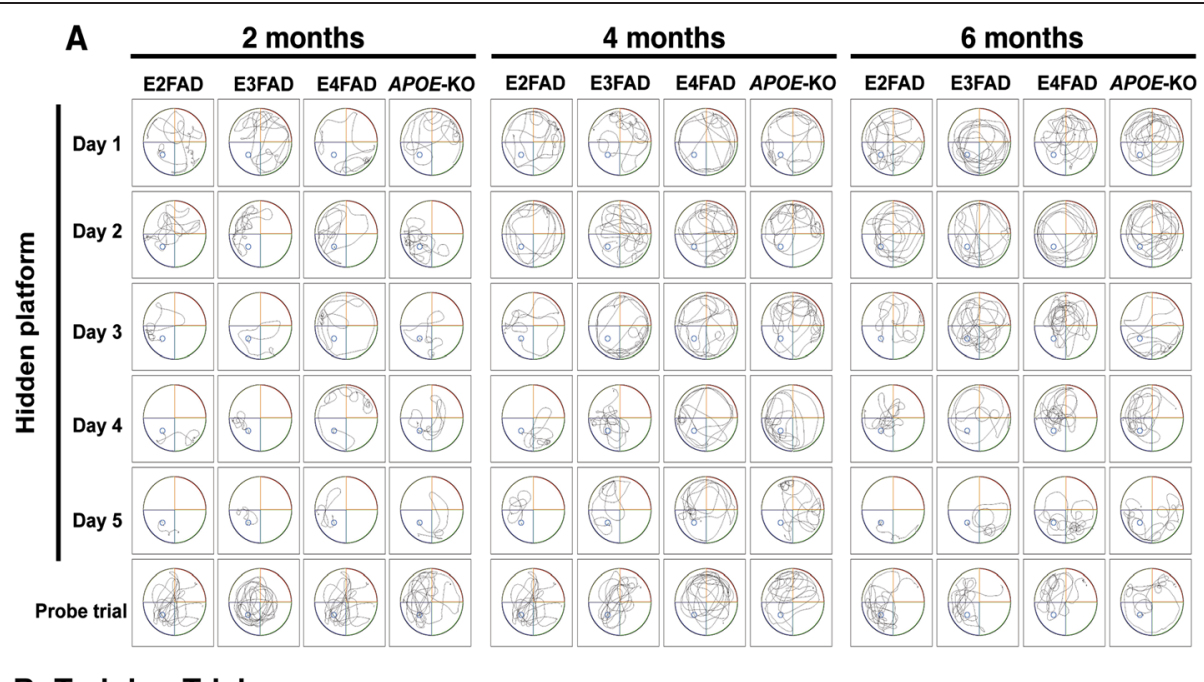

\section{B: Training Trials}

2 months Hidden platform

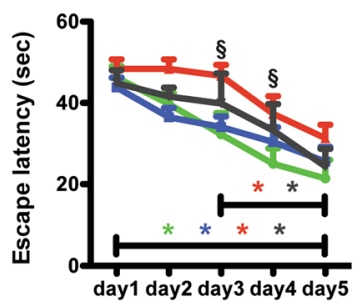

C: Probe Trials

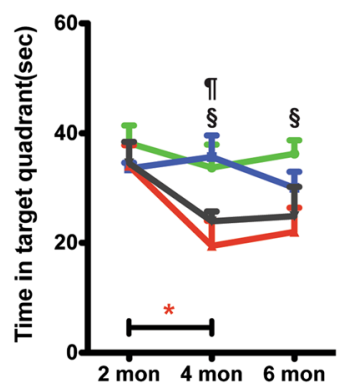

4 months Hidden platform
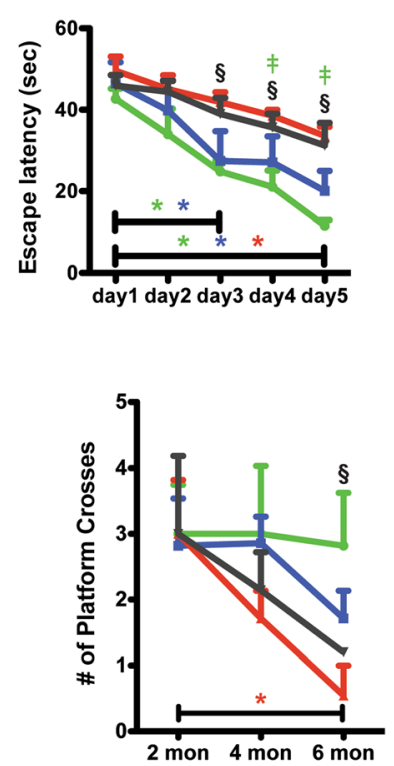

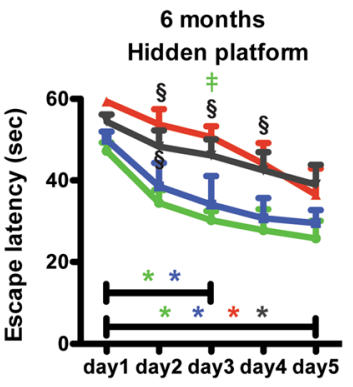

Figure 2 Age-dependent decline in Morris water maze training and performance is exacerbated in E4FAD and 5xFAD/APOE-KO mice compared to E3FAD and E2FAD mice. Results at 2-, 4-, and 6-months of age for E2FAD, E3FAD, E4FAD, and 5xFAD/APOE-KO mice: (A) Representative swimming tracks in Morris water maze for days 1-5 of training (APOE-KO $=5 x F A D / A P O E-K O)$. (B) Training trials: Escape latency for hidden platform. (C) Probe trials: time spent in target quadrant and number of platform crossings. $N \geq 6$ per group, expressed as means \pm S.E.M. Significant differences at $p<$ 0.05 via two-way ANOVA, Bonferroni post-hoc test identified by: "between E2FAD and E3FAD, § between E2FAD and E4FAD, "between E3FAD and E4FAD. Color matched ${ }^{\ddagger}$ (green $=E 2 F A D$, blue $=E 3 F A D$, red $=E 4 F A D$, grey $\left.=5 x F A D / A P O E-K O\right)$ between EFAD strain and 5xFAD/APOE-KO. Along the $x$-axis, color matched *indicates significant differences between time points within a mouse strain. There is no significant change with age unless marked.

term reference memory, are impaired in E4FAD mice compared to E3FAD and E2FAD mice. These data do not support a difference between E4FAD and $5 \times \mathrm{FAD} /$ $A P O E-\mathrm{KO}$ mice $(\mathrm{E} 2 \mathrm{FAD} \geq \mathrm{E} 3 \mathrm{FAD}>\mathrm{E} 4 \mathrm{FAD}=5 \times \mathrm{FAD} /$ $A P O E-\mathrm{KO})$. As with Y-maze, the conclusion is that APOE4 presents primarily as loss of function.
Total apoE levels are lower in E4FAD mice compared to E3FAD and E2FAD mice

Total apoE (Figure 3) levels in the cortex and hippocampus of 2-, 4-, 6-month EFAD and 5xFAD/APOE-KO mice were measured by Western blot (representative blot Figure $3 \mathrm{~A}$ ) and normalized to $\beta$-actin. Two-way 


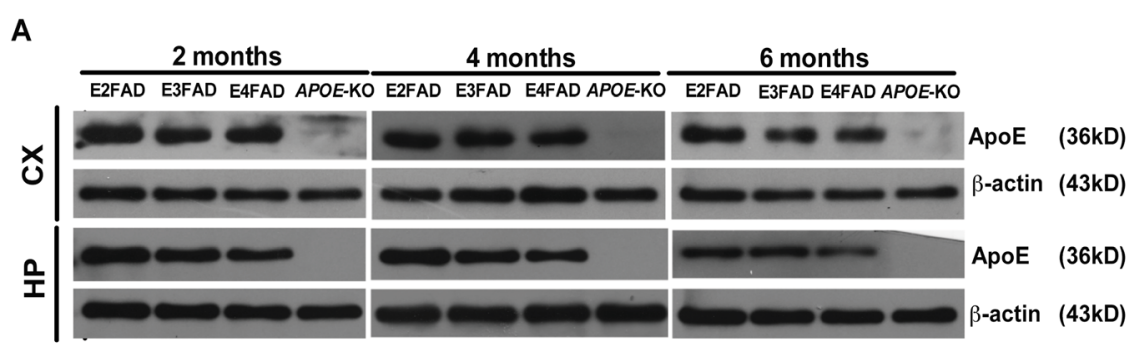

\section{B: Cortex}

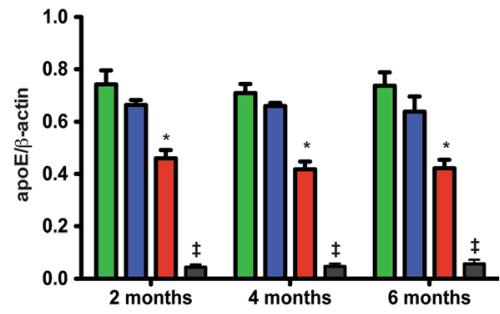

C: Hippocampus

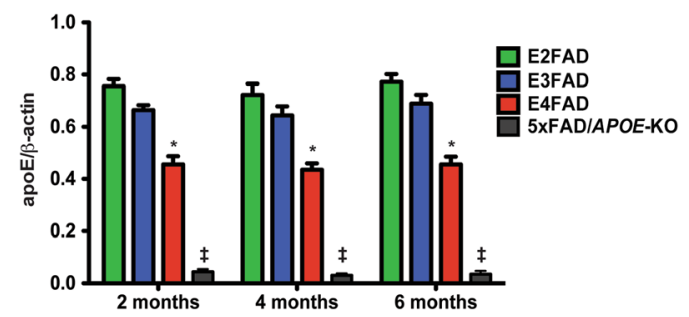

Figure 3 ApoE levels are lower in E4FAD mice compared to E3FAD and E2FAD mice. Results at 2-, 4-, and 6-months of age for E2FAD, E3FAD, E4FAD, and 5XFAD/APOE-KO mice: (A) Representative Western blot for apoE protein in cortex (CX) and hippocampus (HP) with $\beta$-actin as a control for protein loading (APOE-KO $=5 \times \mathrm{FAD} / A P O E-K O)$. Relative apoE protein levels in (B) CX and (C) HP. N = 6 per group, expressed as means \pm S.E.M. Significant difference at $p<0.05$ via two-way ANOVA, Bonferroni post-hoc test identified by *for E4FAD compared to E2FAD and E3FAD. No significant change between time points. ${ }^{\ddagger}$ ApoE levels in 5xFAD/APOE-KO mice were $\geq 10$-fold lower than E4FAD, $p<0.000001$.

ANOVA showed only a genotype effect for apoE levels (Additional file 1). Age had no effect on apoE levels in any genotype in either brain region at any age (Figure 3B, C). However Bonferroni post-hoc analysis, for both brain regions at each age, total apoE4 levels were significantly lower than apoE2 and apoE3 (Figure 3B,C). These data are consistent with previous studies comparing apoE4 levels with apoE3 in humans and mice [48,60-64] and support the few published studies comparing apoE4 with apoE2 levels $[48,60]$. As would be expected, the levels of apoE in the $5 x F A D / A P O E-K O$ mice were just above level of detection and significantly lower than any of the apoE isoforms.

\section{Age-dependent decline in post-synaptic-related protein} levels is exacerbated in E4FAD and 5xFAD/APOE-KO mice compared to E3FAD and E2FAD mice

To begin to dissect potential pathways for apoE4 modulation of cognitive deficits, levels of presynaptic (synaptophysin) and postsynaptic (PSD95, drebrin) proteins were measured in the hippocampus by Western blot (representative blot Figure 4A).

There were no age or genotype effects on the levels of synaptophysin, a presynaptic protein (Figure 4B; twoway ANOVA, Additional file 1). Two-way ANOVA of PSD95 (4C) and drebrin (4C) revealed a significant effect for genotype, age and genotype $\mathrm{X}$ age (Additional file 1). Although post-synaptic proteins PSD95 and drebrin levels were equal among genotypes at 2 months, Bonferroni post-hoc analysis showed significant age effects for both proteins in all genotypes from 2-6 months with the exception of drebrin levels in the E2FAD mice. It is also interesting to note that the decrease in both PSD95 and drebrin for E4FAD and 5xFAD/APOE-KO were significant from 2-4 months, while E3FAD decreased significantly from 4-6 months, and PSD95 levels in E2FAD mice decreased minimally and only from 2-6 months.

In comparisons among the genotypes at each age, both PSD95 and drebrin levels in E2FAD mice were significantly higher than E4FAD and 5xFAD/APOE-KO at 4 and 6 months. Comparisons among genotypes demonstrate that at 4 and 6 months, PSD95 levels were E2FAD $=$ E3FAD > $\mathrm{E} 4 \mathrm{FAD}>5 \mathrm{xFAD} / A P O E-\mathrm{KO}$, evidence for apoE as a loss of function, although there was no difference in drebrin levels between E4FAD and 5xFAD/APOE-KO mice, and these drebrin levels were significantly lower than the drebrin levels in E2FAD and E3FAD mice, with the resulting summary for drebrin: E2FAD $=\mathrm{E} 3 \mathrm{FAD}>\mathrm{E} 4 \mathrm{FAD}=5 \mathrm{xFAD} /$ APOE-KO.

Collectively these data support the observation that postsynaptic proteins are affected prior to presynaptic proteins [38,39,65-67] and this effect may underlie apoE-modulated cognitive deficits. Further, as with cognitive dysfunction, apoE represents primarily a loss of positive function. 
A
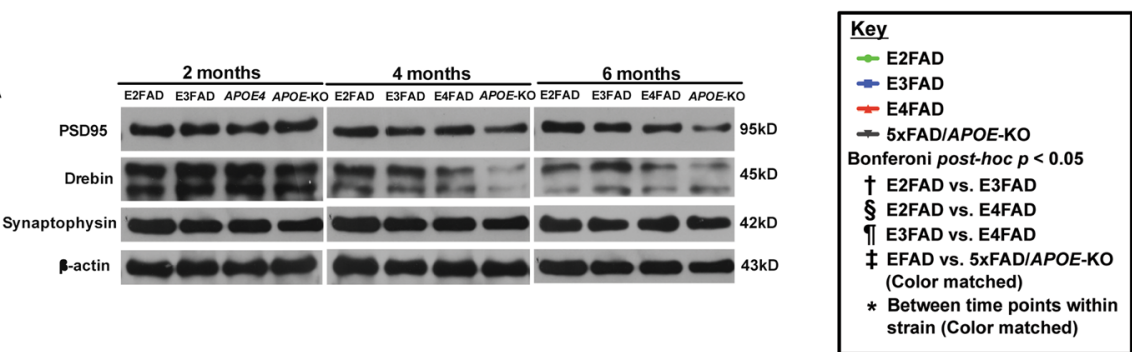

B: Synaptophysin

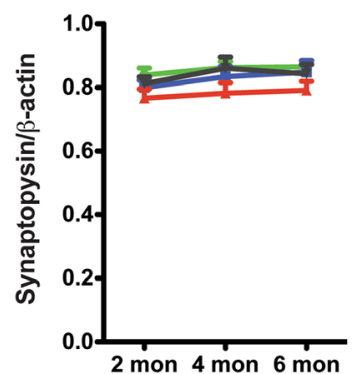

C: PSD95

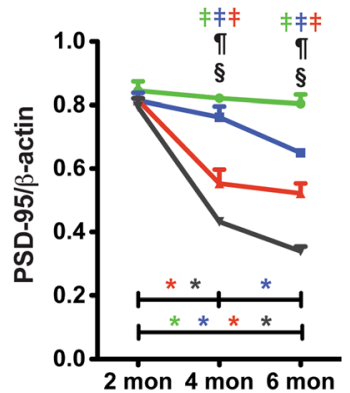

D: Drebrin

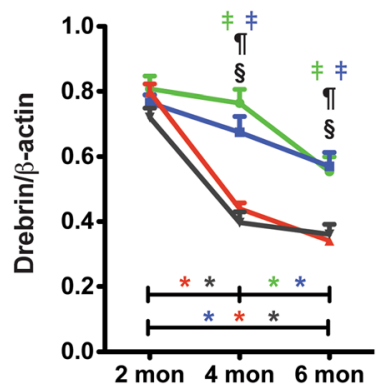

Figure 4 Age-dependent decline in post-synaptic protein levels is exacerbated in 5xFAD/APOE-KO $\geq$ E4FAD mice compared to E3FAD and E2FAD mice. Results at 2-, 4-, and 6-months of age for E2FAD, E3FAD, E4FAD, and 5xFAD/APOE-KO mice: (A) Representative Western blot images for PSD95, drebrin and synaptophysin proteins in HP with $\beta$-actin as a control for protein loading (APOE-KO $=5 \times \mathrm{XAD} / A P O E-K O)$. Relative protein levels of (B) synaptophysin, (C) PSD95 and (D) drebrin. $N=6$ per group, expressed as means \pm S.E.M. Significant differences at $p<0.05$ via two-way ANOVA, Bonferroni post-hoc test identified by: "between E2FAD and E3FAD, § between E2FAD and E4FAD, "between E3FAD and E4FAD. Color matched ${ }^{\ddagger}$ (green $=\mathrm{E} 2 \mathrm{FAD}$, blue $=\mathrm{E} 3 F A D$, red $=\mathrm{E} 4 \mathrm{FAD}$, grey $\left.=5 \times \mathrm{FAD} / A P O E-K O\right)$ between EFAD strain and 5xFAD/APOE-KO. Along the $\mathrm{X}$-axis, color matched *indicates significant differences between time points within a mouse strain. There is no significant change with age unless marked.

Age-dependent decline in NMDAR subunits levels is exacerbated in E4FAD and 5xFAD/APOE-KO mice compared to E3FAD and E2FAD mice

Evidence indicates that reduced postsynaptic NMDAR levels are involved in cognitive dysfunction in AD [37-39]. Therefore, levels of the NMDAR subunits NMDAR1 (Figure 5B), NMDAR2A (Figure 5C) and NMDAR2B (Figure 5D) were measured in the hippocampus by Western blot (representative blot Figure 5A).

Two-way ANOVA of NMDAR results show a significant genotype and age, but no genotype $\mathrm{X}$ age effect (Additional file 1). Further Bonferroni post-hoc analysis revealed that at 2 months, the three NMDAR subunits levels were equal among genotypes except for lower levels of NMDAR1 in 5xFAD/APOE-KO mice, indicating a loss of apoE4 positive function compared to apoE-KO. After 2 months, all three NMDAR subunits in all genotypes decreased from 2-6 months (Figure 5B,C,D), with the exception of, again, E2FAD, consistent with the results for NMDAR2A (Figure 4C). Comparisons among genotypes demonstrate the NMDAR1 levels are consistently higher in E2FAD mice compared to the other genotypes, a trend is also observed for the levels of NMDAR2A and NMDAR2B. While the general trend for the NMDAR subunits is E2FAD and E3FAD being higher than E4FAD and $5 \mathrm{xFAD} / A P O E-\mathrm{KO}$, it is significant to note that NMDAR2B levels are significantly lower in E4FAD compared to $5 \mathrm{xFAD} / A P O E-\mathrm{KO}$ mice at 4 months, with the trend continuing to 6 months, an example of apoE4 gain of toxic function (Figure 5D).

Overall, consistent with cognition and levels of postsynaptic proteins, these data indicates that apoE mediates primarily a loss of positive function with NDMAR subunits levels: E2FAD $\geq \mathrm{E} 3 \mathrm{FAD}>\mathrm{E} 4 \mathrm{FAD} \approx 5 \mathrm{xFAD} /$ APOE-KO.

Age dependent decline in p-CaMK-II levels is significant in E3FAD, E4FAD and 5xFAD/APOE-KO mice compared to E2FAD mice; age dependent decline in p-CREB and BDNF is exacerbated in E4FAD > 5xFAD/APOE-KO $\geq$ E3FAD > E2FAD The NDMAR subunit levels were significantly lower in E4FAD, with a trend in $5 \times \mathrm{xFD} / A P O E-\mathrm{KO}$ mice, compared to E2FAD and E3FAD mice. As reduced levels/ activation of the NMDAR pathway CaMK-II/CREB/ BDNF $[42,68,69]$ are observed in AD patients and associated with impaired neuronal function in vitro and in vivo [70-73], these downstream signaling molecules, specifically the levels of BDNF (Figure 6D) and activated p-CaMK-II (Figure 6B) and pCREB (Figure 6C), were measured in the hippocampus by Western blot 
A
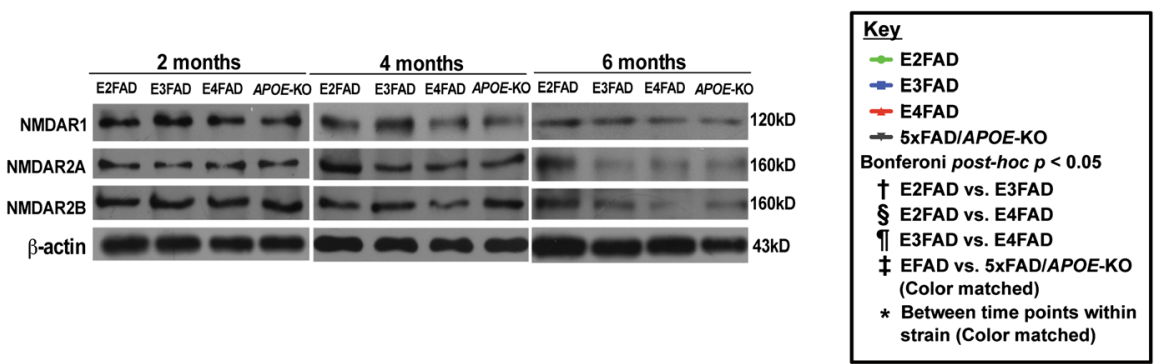

B: NMDAR1

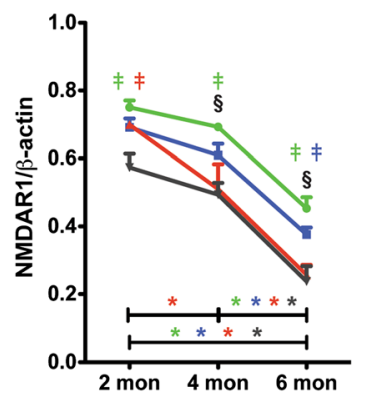

C: NMDAR2A

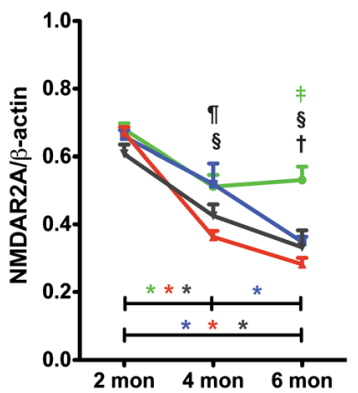

D: NMDAR2B

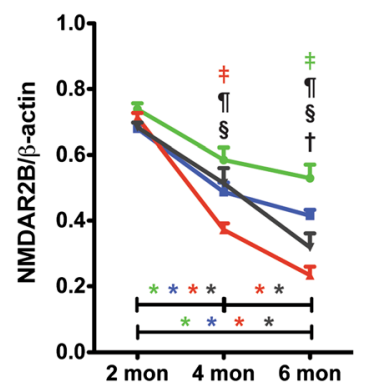

Figure 5 Age-dependent decline in NMDAR subunit protein levels are exacerbated in E4FAD and 5xFAD/APOE-KO compared to E3FAD and E2FAD mice. Results at 2-, 4-, and 6-months of age for E2FAD, E3FAD, E4FAD, and 5xFAD/APOE-KO mice: (A) Representative Western blot for NMDAR1, NMDAR2A and NMDAR2B proteins in HP with $\beta$-actin as a control for protein loading (APOE-KO $=5 \times$ FAD/APOE-KO). Relative protein levels of (B) NMDAR1, (C) NMDAR2A, and (D) NMDAR2B. $N=6$ per group, expressed as means \pm S.E.M. Significant differences at $p<0.05$ via two-way ANOVA, Bonferroni post-hoc test identified by: "between E2FAD and E3FAD, § between E2FAD and E4FAD, "between E3FAD and E4FAD. Color matched ${ }^{\ddagger}$ (green $=\mathrm{E} 2 \mathrm{FAD}$, blue $=\mathrm{E} 3 \mathrm{FAD}$, red $=\mathrm{E} 4 \mathrm{FAD}$, grey $=5 \times \mathrm{FAD} / \mathrm{APOE}-\mathrm{KO}$ ) between EFAD strain and 5xFAD/APOE-KO. Along the $x$-axis, color matched *indicates significant differences between time points within a mouse strain. There is no significant change with age unless marked.

(representative blot Figure 6A). Two-way ANOVA on the p-CaMK-II, p-CREB, and BDNF results showed a significant effect genotype, age and genotype $\mathrm{X}$ age interaction (Additional file 1), Bonferroni post-hoc analysis are detailed below.

$p$-CaMK-II. No differences in p-CaMK-II levels were observed among the genotypes at 2 months (Figure 6B). After 2 months, p-CaMK-II levels decreased from 2-6 months in all the genotypes, although the decrease from 4-6 months was not significant in only E2FAD mice. Comparison among the genotypes at 4 and 6 months, revealed p-CaMK-II levels: E2FAD $>$ E3FAD $=$ E4FAD $=$ 5xFAD/APOE-KO.

$p$-CREB. At 2 months, p-CREB levels were higher in E2FAD and E3FAD mice compared to 5xFAD/APOE$\mathrm{KO}$ mice, and E4FAD levels were lower E2FAD mice (Figure 6C). From 2-6 months, p-CREB levels decreased significantly in all the genotypes but E2FAD. Comparison among the genotypes revealed at 6 months, with a similar trend at 4 months, the levels of p-CREB for the genotypes was E2FAD > E3FAD > 5xFAD/APOE-KO > E4FAD, consistent with a gain of toxic function for apoE4.

$B D N F$. As observed for $\mathrm{p}$-CaMK-II, BDNF levels were not different among the genotypes at 2 months Figure 6D).
After 2 months, BDNF levels decreased with age in the E3FAD, E4FAD and 5xFAD/APOE-KO mice, while levels in E2FAD mice did not change. Comparison among the genotypes revealed that at both 4 and 6 months, the levels of $\mathrm{BDNF}$ for the genotypes was E2FAD $>$ E3FAD $\geq 5 \mathrm{xFAD} /$ $A P O E-K O>$ E4FAD. As with p-CREB, levels of BDNF are consistent with a toxic gain of function for apoE4.

Thus, in contrast to cognitive dysfunction, postsynaptic protein levels (PSD95, drebrin, NDMAR), and pCaMK-II where apoE4 appears to be a loss of function compared to apoE-KO, apoE4 demonstrates a toxic gain of function with $\mathrm{p}-\mathrm{CREB}$ and BDNF levels.

\section{Discussion}

APOE4-induced AD risk is likely the result of multiple, overlapping mechanisms, both $A \beta$-dependent and $A \beta$ independent (for review [74]). One challenge in understanding the effect of $A P O E$ genotype on various mechanistic readouts is determining whether apoE4 represents a loss of positive function or a gain of toxic function. Thus, we investigated the early, age-dependent $A P O E$ genotypespecific effects on cognitive functions and synaptic viability in EFAD-Tg mice $[48,58,59]$, specifically female mice based on data in both humans [53-55] and Tg mice 


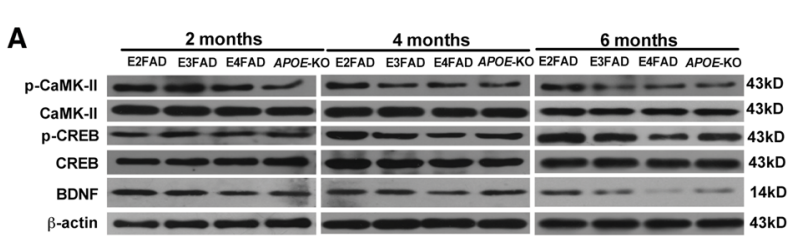

B: p-CaMK-II

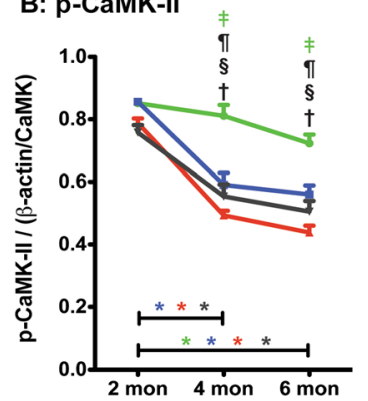

\section{C: $p$-CREB}

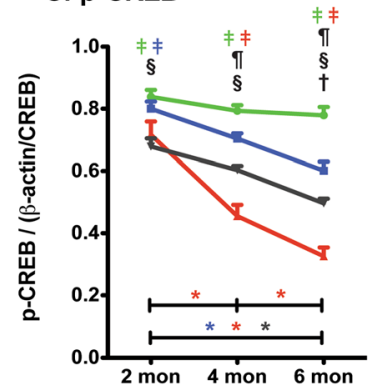

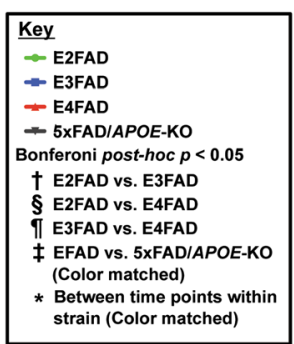

D: BDNF

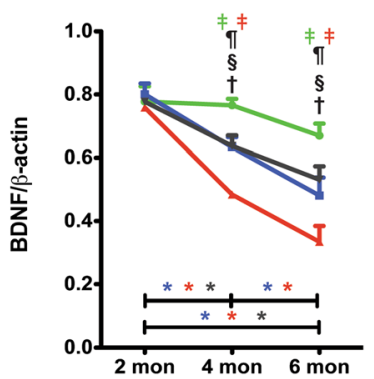

Figure 6 Age-dependent decline in NMDAR-mediated signaling proteins is exacerbated in E4FAD $\geq 5 x F A D / A P O E-K O \geq E 3 F A D>$ E2FAD mice. Results at 2-, 4-, and 6-months of age for E2FAD, E3FAD, E4FAD, and 5xFAD/APOE-KO mice: (A) Representative Western blot images for $\mathrm{p}$-CaMK-II, $\mathrm{p}$-CREB, and BDNF proteins in HP with $\beta$-actin/CREB, $\beta$-actin/CaMK-\|l or $\beta$-actin as a control for protein loading, respectively $(A P O E-K O=$ 5xFAD/APOE-KO). Relative protein levels of (B) p-CaMK-II, (C) p-CREB and (D) BDNF. N $=6$ per group, expressed as means \pm S.E.M. Significant differences at $p<0.05$ via two-way ANOVA, Bonferroni post-hoc test identified by: ${ }^{\dagger}$ between E2FAD and E3FAD, ${ }^{5}$ between E2FAD and E4FAD, "between E3FAD and E4FAD. Color matched ${ }^{\ddagger}$ (green $=E 2 F A D$, blue $=E 3 F A D$, red $=E 4 F A D$, grey $\left.=5 x F A D / A P O E-K O\right)$ between EFAD strain and 5xFAD/APOE-KO. Along the $x$-axis, color matched *indicates significant differences between time points within a mouse strain. There is no significant change with age unless marked.

$[33,35,36,75,76]$ that $A P O E 4$ females exhibit significantly increased cognitive impairment compared to APOE4 males and $A P O E 3$ females. In the Y-maze, a significant age-dependent decline in spatial recognition memory was observed only for the E4FAD mice from 2-4 months, indicating a more rapid decline at earlier stages of $A \beta$ deposition compared to other genotypes (Figure 1). In the MWM, a measure of spatial learning and memory, the E4FAD and 5xFAD/APOE-KO mice were both slower to learn than the E2FAD and E3FAD mice during the 5-day training phase (Figure 2B). In addition, both the E4FAD and $5 \mathrm{xFAD} / A P O E-\mathrm{KO}$ mice exhibited an age-related increase in escape latency from 2-6 months during the training trials, suggesting the failure of some compensatory effect over time. As this is consistent with previous studies demonstrate higher anxiety levels in APOE4-TR and $A P O E-K O$ mice $[76,77]$, we hypothesize that this elevated stress response may facilitate spatial learning in young E4FAD mice and mask adverse effects of apoE4 on spatial cognition. Indeed, it has been shown that normal aging can counteract stress-induced facilitation of cognitive processing in APOE4-TR mice, as measured by MWM, making phenotypic differences easier to detect in older mice $[33,75]$. This apoE4 effect in the EFAD mice is amplified by the overproduction of $A \beta 42$ driven by the presence of the 5-FAD mutations. Indeed, the 5xFAD mice show progressive learning and memory deficits tasks as early as 3 months [78-82]. As deficits in spatial learning and memory due to apoE4 have mainly been reported in older and non-AD mice $[33,75]$, our findings are consistent with synergistic effects between apoE4 and the aggressive $A \beta 42$ pathology characteristic of the EFAD mice [48]. In addition, the use of only female EFAD mice also optimized the risk of cognitive deficits in the E4FAD mice. Indeed, sex interacts with $A P O E$ to affect cognitive function. Clinical data indicate that the $A P O E 4$-induced risk for $\mathrm{AD}$ is significantly greater, perhaps exclusive to, females [53-55]. These data are consistent with the greater cognitive impairment in female APOE4-TR mice compared to female $A P O E 3-T R$ mice, and with both APOE3- and APOE4-TR females compared to $A P O E$ genotype-matched males (review [35]). Overall, as measured in this study, behavior appeared to be primarily an apoE4 loss of function, specifically: E2FAD $=\mathrm{E} 3 \mathrm{FAD}>\mathrm{E} 4 \mathrm{FAD} \approx 5 \mathrm{xFAD} / \mathrm{APOE}-$ KO. However, further studies in humans and Tg-mouse models are critical to determine the role of potential interactive effects among $\mathrm{A} \beta$ pathology, APOE genotype and sex on memory and cognitive decline.

Spatial and learning memory performances are directly linked to synaptic function. ApoE4 is associated with progressive synaptic deficits in both $\mathrm{AD}$ patients and hAPOE-Tg mouse models [83-87]. Consistent with previous 
reports, age-induced reductions in synaptic proteins preferentially occurred in post-synaptic proteins compared particularly to synaptophysin, a pre-synaptic protein (Figure 4) [81,88-90]. In the current model, levels of drebrin and PSD95 were lower in E4FAD and 5xFAD/ APOE-KO mice compared to E2FAD and E3FAD mice, consistent with an apoE4 loss of function. ApoE is also linked to long-term potentiation (LTP) and NMDARmediated signaling $[50,51]$. As the NMDAR component of synaptic transmission has been shown to decline during aging [91,92], NMDAR activation may provide a mechanistic pathway for understanding apoE-related memory impairment. Indeed, in this study apoE-related cognitive impairment correlates with a decrease in the levels of NMDR subunits and components of the signaling pathway (p-CaMK-II/p-CREB/BDNF). Levels of all three NMDAR subunits were reduced with age for all the genotypes with reductions greater in the E4FAD and 5xFAD/APOE-KO mice compared to E2FAD and E3FAD mice, consistent with an apoE4 loss of function (Figure 5). These apoE4related deficits in NMDAR-dependent functions likely reflect changes to neuronal networks contributing to short and long-term memory, and their contribution to memory consolidation [93-96]. Reduction of BDNF levels through either genetic or pharmacological means not only impaired LTP and reduced the number of synapses, but also caused deficits in the formation and consolidation of memory [97-99]. However, the effects of $A P O E$ genotype on the p-CaMK-II, p-CREB, and BDNF signaling cascade are not consistent. Again, all the signaling components were reduced with age for all the genotypes (Figure 6). While the greater reduction in p-CaMK-II in E4FAD and 5xFAD/APOE-KO mice compared to E2FAD and E3FAD mice is consistent with an APOE4 loss of function, apoE4 represents a gain of toxic function for both the activated p-CREB transcription factor and its downstream target protein BDNF, as the reductions in $\mathrm{p}-\mathrm{CREB}$ and $\mathrm{BDNF}$ levels are greater in E4FAD compared to 5xFAD/APOE$\mathrm{KO}$ mice (summarized in Figure 7, right side). This gain of toxic function does not translate directly to the behavioral measures used in this study. One likely possibility for this seeming disconnect is that a number of signaling pathways are activated by changes in synaptic proteins, particularly the NMDAR, that eventually converge to modulate behavioral readouts. Thus, the final effect on behavior will be a composite of a number of signaling pathways (reviewed in [100]). Taken together, our findings support the notion that apoE4 exacerbates behavioral deficits in EFAD mice by decreasing synapse viability by reducing synapserelated proteins, particularly via down-regulation of NMDAR and NMDAR-mediated signaling via CaMK-II, $\mathrm{CREB}$, and BDNF (Figure 7). Consistent with the APOE2 protective effect for $A D$ risk [1-11], these results also demonstrate that E2FAD mice are consistently less susceptible to age-induced changes in the components of this cascade, from signaling to behavior.

ApoE is the primary ligand for the low-density lipoprotein (LDL) receptor (LDLR) family (apoE receptors), although Reelin is the primary ligand for ApoE-receptor 2 (ApoER2). ApoER2 and Reelin are important modulators of synaptic plasticity and NMDAR functions in vitro and in vivo [106-108]. Thus, the association between ApoER2, Reelin and NMDAR are critical for LTP, memory formation and retrieval. ApoE4 has been demonstrated to reduce the cell-surface levels of both ApoER2 and NMDAR via intracellular sequestration, thus inhibiting the ability of Reelin to facilitate glutamate-mediated synaptic plasticity [46]. The impaired recycling of apoE4 may contribute to this reduction in receptors at the cell surface [105]. Loss of ApoER2 reduces Reelin binding, thus further reducing activation of NMDAR via signaling by the Src family kinases $[46,105]$.

While a number of $\mathrm{A} \beta$-independent mechanisms likely contribute to the $A P O E$-associated risk for AD [109], $\mathrm{oA} \beta$ has been demonstrated to be preferentially synapotoxic (for review [37,110]). We have published the effects of $A P O E$ genotype on $A \beta$ accumulation in the EFAD mice at 6-months of age, the age of the mice used for this study $[48,58,59,111,112]$. These results demonstrate amyloid deposition by IHC and total brain $A \beta 42$ by ELISA is: 5xFAD $>$ E4FAD $>$ E3FAD $=$ E2FAD. A threestep sequential protein extraction protocol using TBS (soluble), TBS + Triton X-100 (TBSX, detergent), and formic acid (FA, insoluble) was used for the hippocampus and cortex. In the soluble fractions of both brain regions, both $A \beta 42$ and $\mathrm{OA} \beta$ are: E4FAD > E3FAD = E2FAD. There is no APOE genotype difference in the levels of $A \beta 42$ in the detergent fraction. In the insoluble fraction, $\mathrm{A} \beta 42$ is: E4FAD > E3FAD = E2FAD. As the EFAD mice are on the 5xFAD background, the amount of $A \beta 40$ is difficult to detect; the primary species is $A \beta 42$. Thus, $A \beta$ levels (amyloid, soluble and insoluble) are greatest in the E4FAD mice. This association between $A P O E$ and $\mathrm{A} \beta$ accumulation is consistent with the functional changes reported herein. Therefore, a particularly relevant approach to interpreting the results of this study is to consider $A P O E$ modulation of soluble $\mathrm{A} \beta$ levels at the synapse (Figure 7, left side). Previous publications from our group and others demonstrate that apoE isoform-specific effects on $A \beta$ clearance and interactions with apoE receptors likely play a role in this process at several levels. It has been specifically demonstrated that apoE4 both increases the levels of oA $\beta$ and directs it to the synapse [5]. ApoE isoforms may modulate oA $\beta$ levels through differential apoE/A $\beta$ complex levels [113]. However, as isolation and analysis of the apoE/A $\beta$ complex in vivo is technically challenging, data are conflicting as to the significance or even the existence 


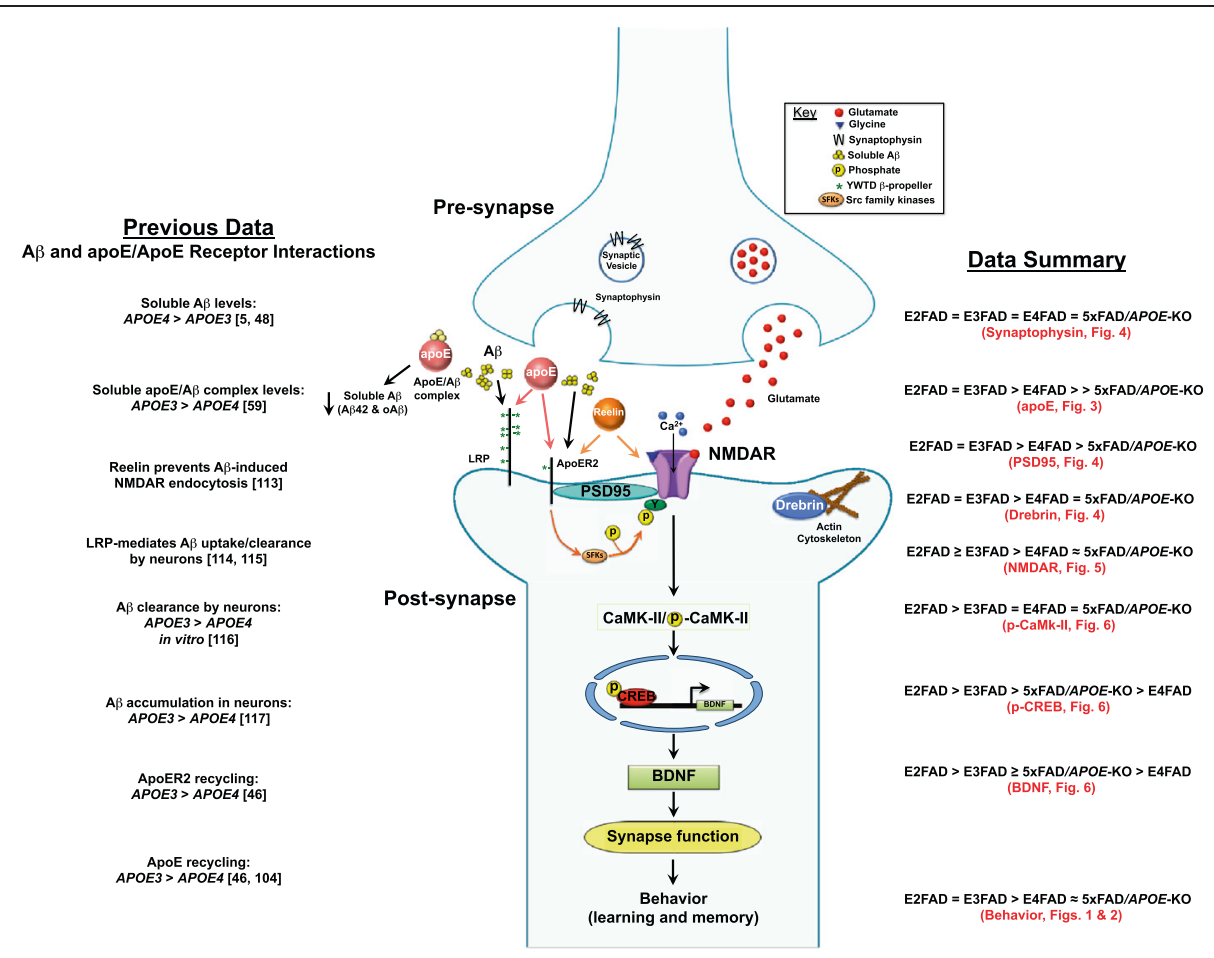

Figure 7 Diagram of potential APOE4-induced decrease in synapse-related proteins and disruption of NMDAR-mediated signaling, resulting in impaired learning and memory. With $A P O E 4$, the levels of key post-synaptic proteins are reduced, including the subunits of NMDAR. NMDAR signaling via activation by phosphorylation of CaMK-II and CREB to increase expression of BDNF is also disrupted by APOE4, compromising synaptic function and impairing learning and memory. Previous work has demonstrated that apoE isoform-specific effects on $A \beta$ clearance and interactions with apoE receptors likely play a role in this process at several levels. Soluble levels of $A \beta$ are lower with apoE3 and inversely correlated with levels of apoE3/A $\beta$ complex [59], suggesting a potential clearance mechanism. LRP mediates A $\beta$ uptake by neurons $[101,102]$, and, in vitro, $A \beta$ clearance is impaired with apoE4 [103], consistent with a greater accumulation of intraneuronal A [104] compared to apoE3. For ApoER2, ligand recycling is impaired with apoE4 compared to apoE3 [46]. Loss of ApoER2 reduces Reelin binding, thus reducing activation of NMDAR via signaling by the Src family kinases [46,105], leading to decreased synaptic function and therefore decreased learning and memory.

of this complex [114-116]. Nevertheless, it is interesting to note that the levels of soluble apoE4/A $\beta$ complex are lower than apoE3/A $\beta$ and decrease in $\mathrm{AD}$ in human synaptosomes, CSF and EFAD-Tg mouse brains, the reverse of soluble oA $\beta$ levels $[48,58,59,113]$. ApoE receptors also play a key role, particularly ApoER2, as Reelin signaling can prevent the oA $\beta$-induced inhibition of NMDAR at the synapse [117]. As well, neuronal LRP1 provides a significant mechanism for the clearance $A \beta[101,102]$ and in vitro, $\mathrm{A} \beta$ clearance is impaired with apoE4, compared to apoE3 [103], consistent with a greater accumulation of intraneuronal $A \beta$ [104]. To connect these $A \beta$-dependent processes to decreased synaptic function and impaired cognition requires, in part, a return to ApoER2, NMDAR and Reelin. ApoE4 induces deficits in ApoER2 and NMDAR signaling and recycling, as well as reducing Reelin binding to both receptors [46,105]. Ultimately, these apoE-mediated differential effects on apoE receptors and $A \beta$ accumulation could contribute to the mechanisms responsible for synaptic dysfunction and cognitive decline characteristic of observed in the EFAD mice that, ultimately, will translate to AD patients.

\section{Conclusions}

Herein we provide evidence that the APOE4 genotype constitutes a loss of positive function contributing to age-related deficits in behavioral performances in the EFAD and 5xFAD/APOE-KO mice (Figure 7-right side; Table 1A). This loss of positive function with apoE4 was related to a decrease in post-synaptic proteins, including NMDAR subunits, leading to impaired NMDAR-related signaling. However, apoE4 represents a gain of toxic function for the final components measured in this pathway, activated $\mathrm{p}$-CREB and its downstream target protein BDNF. It is our interpretation that multiple signaling pathways converge to determine the final synaptic transmission impairment and learning and memory deficits associated with apoE4. This conclusion requires further study to determine the potential contributions of other signaling components to either an apoE4-mediated loss or gain of 
Table 1 Evidence that APOE4 is a loss of positive or gain of negative function: comparison to absence of $A P O E$

\begin{tabular}{|c|c|c|c|}
\hline \multicolumn{4}{|l|}{ A. Within manuscript } \\
\hline Measure & apoE4 represents: & \multicolumn{2}{|l|}{ Mouse model } \\
\hline Behavior/cognition & Loss of function & \multicolumn{2}{|l|}{ 5xFAD/APOE-KO, EFAD } \\
\hline Postsynaptic protein levels & Loss of function & & \\
\hline NMDAR subunits & Loss of function & & \\
\hline p-CaMK-II levels & Loss of function & & \\
\hline p-CREB levels & Gain of toxic function & & \\
\hline BDNF levels & Gain of toxic function & & \\
\hline \multicolumn{4}{|l|}{ B. Literature overview } \\
\hline Measure & apoE4 represents: & Mouse model & Reference \\
\hline Anti-inflammatory & Loss of function & APOE-KO, APOE-TR & [47] \\
\hline Baseline LTP & Loss of function & $\begin{array}{l}\text { WT, APOE-KO, APOE-TR } \\
\text { (Ex vivo hippocampal slice cultures) }\end{array}$ & {$[50]$} \\
\hline \multirow[t]{4}{*}{ Amyloid deposition } & \multirow[t]{4}{*}{ Loss of function } & APOE-KO $\times \mathrm{APP}^{\mathrm{V} 717+/-}$ & [118], \\
\hline & & $\mathrm{APP}^{\mathrm{V} 717+/-} \times \mathrm{GFAP} \mathrm{apoE}^{+/-}$ & {$[119,120]$} \\
\hline & & \multirow[t]{2}{*}{ 5xFAD, EFAD } & {$[48]$} \\
\hline & & & for review, [35] \\
\hline \multirow[t]{2}{*}{ ApoE lipidation } & \multirow[t]{2}{*}{ Loss of function } & APOE-TR & [121] \\
\hline & & EFAD & {$[58]$} \\
\hline Dendritic spine density & Loss of function & WT, APOE-KO, GFAP-apoE ${ }^{+/+}$ & [84] \\
\hline BBB integrity & Loss of function & $\mathrm{WT}, A P O E-\mathrm{KO}, A P O E-\mathrm{TR}, \mathrm{GFAP}-A P O E$ & [122] \\
\hline$A B$ clearance across the BBB & Loss of function & WT, $\mathrm{APOE}^{+/-}, \mathrm{APOE}-\mathrm{KO}$ & [123] \\
\hline \multirow[t]{5}{*}{ Behavior/cognition } & \multirow[t]{5}{*}{ Gain of toxic function } & WT, APOE-KO, APOE-TR & [33] \\
\hline & & WT, APOE-KO, APOE-TR & [34] \\
\hline & & WT, APOE-KO, GFAP-apoE & [124] \\
\hline & & WT, APOE-KO, GFAP-apoE (female) & [125] \\
\hline & & WT, APOE-KO, NSE-apoE & {$[124,126]$} \\
\hline Accumulation of intraneuronal $\mathrm{OA} \beta$ & Gain of toxic function & APOE-KO, APOE-TR & [127] \\
\hline \multirow[t]{2}{*}{ oA $\beta$-induced neurotoxicity } & \multirow[t]{2}{*}{ Gain of toxic function } & WT, APOE-KO, APOE-TR & {$[52]$} \\
\hline & & In vitro neuron/glial co-cultures & \\
\hline oAß-dependent inhibition of LTP & Gain of toxic function & APOE-KO, APOE-TR & [51] \\
\hline Neurotoxicity of apoE proteolytic fragments & Gain of toxic function & Variety with $A P O E-K O$ control & {$[75,128]$ for review, $[129]$} \\
\hline \multirow[t]{2}{*}{ Neurite outgrowth } & Loss of function & $\begin{array}{l}\text { APOE-KO olfactory epithelia cultures } \\
\text { (exogenous apoE added) APOE-KO }\end{array}$ & [130] \\
\hline & Gain of toxic function & cortical neuron cultures (exogenous apoE added) & [131] \\
\hline
\end{tabular}

function, data of high therapeutic significance. Table $1 \mathrm{~B}$ provides a representative summary of CNS-relevant functions modulated by apoE4 that can be attributed to a loss of positive or gain of toxic function. Again, it is important to assess whether apoE4 imparts a loss of positive or gain of toxic function in comparison to the absence of apoE (APOE-KO), not simply a comparison to apoE2/apoE3. Table $1 \mathrm{~B}$ provides a larger perspective on the interplay between among multiple functions that exhibit a loss of positive (for example, anti-inflammatory properties and amyloid deposition) or gain of toxic function (for example, toxic proteolytic fragments of apoE and oA $\beta$ induced neurotoxicity in vitro and ex vivo). Only an understanding of the relative contribution of the functions measured in this paper, listed in Table 1A and the many others as yet undefined will enable a confident identification of $A P O E 4$-induced $\mathrm{AD}$ risk as a loss of positive or gain of toxic function.

Targeting the most potent genetic risk factor for $\mathrm{AD}$ appears a very attractive strategy and is still under intense study. If the hypothesis is that all apoE isoforms, particularly apoE4, represent a toxic gain of function, 
then reducing $A P O E$ expression and/or apoE levels is one therapeutic approach for AD. However, the potential dangers of this approach in the human brain are still subjected to debate [30]. Here, we provide additional insight into the mechanism by which APOE4 increases $\mathrm{AD}$ risk, in which apoE4 mainly appears as a loss of positive function. Accordingly, rather than $A P O E$ gene inactivation, therapies that correct the loss of positive function related to apoE4, such as increasing the lipidation of apoE4 containing lipoproteins [58] appear to be more appropriate.

\section{Methods}

\section{Animals}

All experiments were conducted in accordance with the rules and regulations of the Institutional Animal Care and Use Committee protocols at Fujian Medical University, in conformance with international guidelines for the ethical use of animals. Investigators conducting the sample processing and analyses were blinded for $A P O E$ genotype and age. The 5xFAD/APOE-KO and EFAD mice (E2FAD, E3FAD, and E4FAD) were supplied by the $\mathrm{LaDu}$ lab. The EFAD mice [48] were originally generated by crossing 5xFAD mice [57] and h-APOE-TR mice [56]. 5xFAD mice express APP K670N/M671L + I716V + V717I and PS1 M146L + L286V under the control of the neuron-specific mouse Thy-1 promoter, resulting in the overproduction of specifically $\mathrm{A} \beta 42$ [57]. In $A P O E-\mathrm{TR}$ mice, the coding domain of $\mathrm{m}$-apoE is replaced by $\mathrm{h}$ apoE2, apoE3 or apoE4 [56]. Thus, EFAD mice are APOE$\mathrm{TR}^{+/+} / 5 \mathrm{xFAD}^{+/}[48]$. The $5 \mathrm{xFAD} / A P O E-\mathrm{KO}$ mice were made by knocking-out $\mathrm{m}-A P O E$ from the $5 \mathrm{xFAD}$ mice.

\section{Behavioral tests}

Spatial/reference memory was assessed in EFAD mice first using the Y-maze test, followed by the Morris water maze (MWM) test, as previous described [90,132]. Y-maze. Spontaneous alteration including total activity and percentage spontaneous alternation/exploration was initially determined as a measure of normal spatial navigation. Short-term spatial recognition memory was then assessed using a two-trial protocol with 10 minute $(\mathrm{min})$ training (trial 1), 4 hour (hr) inter-trial interval and a 5 min retention trial (trial 2) for number of entries and time spent in each arm. MWM. Acquisition trials (training) consisted of 4 trials (maximum $1 \mathrm{~min}$ ) a day for 5 consecutive days with escape latency recorded for each trial. Reference memory was assessed on the sixth day in a one trial test for time spent in the target quadrant and the number of times the original area of the platform was crossed.

\section{Tissue harvest and western blotting}

2-, 4- and 6-month EFAD mice were anesthetized with sodium pentobarbital $(50 \mathrm{mg} / \mathrm{kg})$, transcardially perfused with ice-cold PBS, brains removed and dissected into cortex and hippocampus, snap-frozen in liquid nitrogen and stored at $-80^{\circ} \mathrm{C}$, as previous described [133]. Dissected brains were homogenized in lysis buffer $[90,132]$ (50 mM Tris-HCl, $150 \mathrm{mM} \mathrm{NaCl}, \mathrm{pH} 7.4,1 \%$ Triton X100, 1x protease inhibitor cocktail) and $40 \mu \mathrm{g}$ of total protein (BCA protein assay kit; Pierce, Rockford, IL) was separated on $4-12 \%$ gradient Bis-Tris gels (Invitrogen) under reducing conditions, and transferred to PVDF membranes [47]. The following primary antibodies were used: rabbit anti-PSD95 (1:3000, Abcam), mouse antisynaptophysin (1:2000, Abcam), mouse/rabbit anti- $\beta$ actin (1:2000; Abcam), rabbit anti-drebrin antibody (1:1000; Abcam), rabbit anti-NMDAR1/anti-NMDAR2B (1:1000; Millipore), anti-NMDAR2A (1:500; Millipore), mouse anti-apoE (1:600; Santa Cruz), rabbit anti-BDNF (1:200; Santa Cruz), rabbit anti-p-CaMK-II (1:1000; Santa Cruz) and rabbit anti-p-CREB (1:1000; Cell Signaling) $[90,132]$. HRP-conjugated secondary antibodies, enhanced chemiluminescence (Amersham, Piscataway, NJ) and Image $\mathrm{J}$ software were used to quantify densities of the immunoreactive bands relative to $\beta$-actin.

\section{Statistical analysis}

Data are expressed as mean \pm standard error mean (S.E. M.). Data were analyzed by two-way analysis of variance (ANOVA), followed by Bonferroni post-hoc using GraphPad Prism version 4 for Macintosh. The 2-way ANOVA tables for each Figure have been added as Additional file 1 . Differences for age and genotype were considered significant for $p<0.05 ; \mathrm{n} \geq 6$.

\section{Additional file}

Additional file 1: Two-way ANOVA Tables.

\section{Abbreviations}

Aß: Amyloid- $\beta$; AD: Alzheimer's disease; apoE: Apolipoprotein E; ApoER2: ApoE receptor 2; BDNF: Brain derived neurotropic factor; CaMK-II: Calcium/calmodulindependent protein kinase-ll; CREB: CAMP-response element binding protein; EFAD mice: Tg-mice expressing 5XFAD mutations and human APOE2, APOE3, or APOE4; FAD: Familial-AD; h: Human; KO: Knockout; LTP: Long-term potentiation; m: Mouse; min: Minute; MWM: Morris water maze; NMDAR: N-methyl-D-aspartate receptor; OAB: Oligomeric amyloid- $\beta$; p: Phosphorylated; $p$-CREB: Phosphorylated cAMP-response element binding protein; p-CaMK-Il: Phosphorylated calcium/ calmodulin-dependent protein kinase-ll; PSD95: Postsynaptic density protein 95; Tg: Transgenic; TR: Targeted replacement; 5xFAD: Tg mice expressing 5 FAD mutations; 5XFAD/APOE-KO: 5xFAD mice with m-APOE-KO.

\section{Competing interests}

The authors declare that they have no competing interests.

\section{Authors' contributions}

D-s L: Provided substantial contributions to project conception, experimental design and manuscript preparation. X-d P: Provided substantial contributions to project conception, experimental design and manuscript preparation. JZ: Preformed Y-maze behavior tests and complied data for Figure 1. HS:

Preformed MWM behavior tests and complied data for Figure 2. NCC: Generated Figures 1, 2, 3, 4, 5, 6 and 7 in collaboration with AMC and MJLD and contributed 
to interpretation of the results and preparation of the manuscript. AMC: Generated Figure 7 in collaboration with NCC and contributed to the preparation of the manuscript. KPK: Generated Table 1 and contributed to interpretation of literature for the manuscript. MBA: Contributed to interpretation of the results and preparation of the manuscript. X-m D: Generated Western Blots and analysis for Figures 3, 4, 5, and 6 in collaboration with MZ. MZ: Generated Western Blots and analysis for Figures 3, 4, 5, and 6 in collaboration with X-m D. LMT: Contributed to interpretation of the results and prepared the manuscript in collaboration with MJLD. Y-g Z: Tissue harvest and homogenization for Figures 3, 4, 5 and 6. MJLD: Provided fundamental contributions to interpretation of results, writing and revision of the manuscript. X-c C: Provided substantial contributions to project conception, experimental design and manuscript preparation and revision. All authors read and approved the final manuscript.

\section{Acknowledgements}

These studies were funded by National Natural Science Foundation of China 81171216 (X-cC); National Natural Science Grant of China No. 81200991 and Fujian Province New Century Excellent Talents Support Program, China JA13131 (X-dP); National Natural Science Foundation of China No. 81071007 (Y-gZ); and Alzheimer's Drug Discovery Foundation Grant, NIH/NIA P01AG030128, NIH/NIA R21AG048498, and University of Illinois at Chicago Center for Clinical and Translational Science Grant UL1RR029879 (MJL).

\section{Author details}

${ }^{1}$ Department of Neurology, Fujian Medical University Union Hospital, 29 Xinquan Road, 350001 Fuzhou, China. ${ }^{2}$ Fujian Institute of Geriatrics, Fujian Medical University Union Hospital, 29 Xinquan Road, 350001 Fuzhou, China. ${ }^{3}$ Key Laboratory of Brain Aging and Neurodegenerative Disease, Fujian Key Laboratory of Molecular Neurology, Fujian Medical University, 29 Xinquan Road, 350001 Fuzhou, China. ${ }^{4}$ Department of Anatomy and Cell Biology, University of Illinois at Chicago, 808 S.Wood St., M/C 512, 60612 Chicago, IL, USA.

\section{Received: 26 November 2014 Accepted: 26 January 2015} Published online: 05 March 2015

\section{References}

1. Corder EH, Saunders AM, Strittmatter WJ, Schmechel DE, Gaskell Jr PC, Rimmler JB, et al. Apolipoprotein E, survival in Alzheimer's disease patients, and the competing risks of death and Alzheimer's disease. Neurology. 1995:45:1323-8

2. Roses AD. Apolipoprotein E genotyping in the differential diagnosis, not prediction, of Alzheimer's disease. Ann Neurol. 1995;38:6-14

3. Kim D, Tsai LH. Bridging physiology and pathology in AD. Cell. 2009;137:997-1000.

4. Leduc V, Jasmin-Belanger S, Poirier J. APOE and cholesterol homeostasis in Alzheimer's disease. Trends Mol Med. 2010;16:469-77.

5. Koffie RM, Hashimoto T, Tai HC, Kay KR, Serrano-Pozo A, Joyner D, et al. Apolipoprotein E4 effects in Alzheimer's disease are mediated by synaptotoxic oligomeric amyloid-beta. Brain. 2012;135:2155-68.

6. Corder EH, Saunders AM, Strittmatter WJ, Schmechel DE, Gaskell PC, Small $\mathrm{GW}$, et al. Gene dose of apolipoprotein E type 4 allele and the risk of Alzheimer's disease in late onset families. Science. 1993;261:921-3.

7. Saunders AM, Strittmatter WJ, Schmechel D, George-Hyslop PH, PericakVance MA, Joo SH, et al. Association of apolipoprotein E allele epsilon 4 with late-onset familial and sporadic Alzheimer's disease. Neurology. 1993:43:1467-72.

8. Houlden H, Crook R, Backhovens H, Prihar G, Baker M, Hutton M, et al. ApoE genotype is a risk factor in nonpresenilin early-onset Alzheimer's disease families. Am J Med Genet. 1998;81:117-21.

9. Breitner JC, Jarvik GP, Plassman BL, Saunders AM, Welsh KA. Risk of Alzheimer disease with the epsilon4 allele for apolipoprotein $\mathrm{E}$ in a population-based study of men aged 62-73 years. Alzheimer Dis Assoc Disord. 1998;12:40-4.

10. Farrer LA, Cupples LA, Haines JL, Hyman B, Kukull WA, Mayeux R, et al. Effects of age, sex, and ethnicity on the association between apolipoprotein E genotype and Alzheimer disease. A meta-analysis. APOE and Alzheimer Disease Meta Analysis Consortium. JAMA. 1997;278:1349-56.

11. Khachaturian AS, Corcoran CD, Mayer LS, Zandi PP, Breitner JC. Apolipoprotein E epsilon4 count affects age at onset of Alzheimer disease, but not lifetime susceptibility: The Cache County Study. Arch Gen Psychiatry. 2004;61:518-24.

12. Roses AD. Apolipoprotein E alleles as risk factors in Alzheimer's disease Annu Rev Med. 1996;47:387-400.

13. Reitz C, Mayeux R. Use of genetic variation as biomarkers for mild cognitive impairment and progression of mild cognitive impairment to dementia. J Alzheimers Dis. 2010;19:229-51.

14. Leoni $\mathrm{V}$. The effect of apolipoprotein $E$ (ApoE) genotype on biomarkers of amyloidogenesis, tau pathology and neurodegeneration in Alzheimer's disease. Clin Chem Lab Med. 2011;49:375-83.

15. Bu G. Apolipoprotein E and its receptors in Alzheimer's disease: pathways, pathogenesis and therapy. Nat Rev Neurosci. 2009;10:333-44.

16. Liu CC, Kanekiyo T, Xu H, Bu G. Apolipoprotein E and Alzheimer disease: risk, mechanisms and therapy. Nat Rev Neurol. 2013;9:106-18.

17. Lue LF, Kuo YM, Roher AE, Brachova L, Shen Y, Sue L, et al. Soluble amyloid beta peptide concentration as a predictor of synaptic change in Alzheimer's disease. American J Pathol. 1999;155:853-62.

18. McLean CA, Cherny RA, Fraser FW, Fuller SJ, Smith MJ, Beyreuther K, et al. Soluble pool of Abeta amyloid as a determinant of severity of neurodegeneration in Alzheimer's disease. Ann Neurol. 1999;46:860-6.

19. Wang J, Dickson DW, Trojanowski JQ, Lee VM. The levels of soluble versus insoluble brain Abeta distinguish Alzheimer's disease from normal and pathologic aging. Exp Neurol. 1999;158:328-37.

20. Tomic JL, Pensalfini A, Head E, Glabe CG. Soluble fibrillar oligomer levels are elevated in Alzheimer's disease brain and correlate with cognitive dysfunction. Neurobiol Dis. 2009;35:352-8.

21. Jin M, Shepardson N, Yang T, Chen G, Walsh D, Selkoe DJ. Soluble amyloid beta-protein dimers isolated from Alzheimer cortex directly induce Tau hyperphosphorylation and neuritic degeneration. Proc Natl Acad Sci U S A. 2011;108:5819-24.

22. Kuo YM, Emmerling MR, Vigo-Pelfrey C, Kasunic TC, Kirkpatrick JB, Murdoch $\mathrm{GH}$, et al. Water-soluble Abeta (N-40, N-42) oligomers in normal and Alzheimer disease brains. J Biol Chem. 1996;271:4077-81.

23. Selkoe DJ. Resolving controversies on the path to Alzheimer's therapeutics. Nat Med. 2011;17:1060-5.

24. Cosentino S, Scarmeas N, Helzner E, Glymour MM, Brandt J, Albert M, et al. APOE epsilon 4 allele predicts faster cognitive decline in mild Alzheimer disease. Neurology. 2008:70:1842-9.

25. Carrasquillo MM, Crook JE, Pedraza O, Thomas CS, Pankratz VS, Allen M, et al. Late-onset Alzheimer's risk variants in memory decline, incident mild cognitive impairment, and Alzheimer's disease. Neurobiol Aging. 2014:36:60-7.

26. Caselli RJ, Dueck AC, Osborne D, Sabbagh MN, Connor DJ, Ahern GL, et al. Longitudinal modeling of age-related memory decline and the APOE epsilon4 effect. N Engl J Med. 2009;361:255-63.

27. Caselli RJ, Reiman EM, Locke DE, Hutton ML, Hentz JG, Hoffman-Snyder C, et al. Cognitive domain decline in healthy apolipoprotein E epsilon4 homozygotes before the diagnosis of mild cognitive impairment. Arch Neurol. 2007:64:1306-11.

28. Christensen H, Batterham PJ, Mackinnon AJ, Jorm AF, Mack HA, Mather KA, et al. The association of APOE genotype and cognitive decline in interaction with risk factors in a 65-69 year old community sample. BMC Geriatr. 2008;8:14.

29. Schiepers OJ, Harris SE, Gow AJ, Pattie A, Brett CE, Starr JM, et al. APOE E4 status predicts age-related cognitive decline in the ninth decade: longitudinal follow-up of the Lothian Birth Cohort 1921. Mol Psychiatry. 2012;17:315-24

30. Mak AC, Pullinger CR, Tang LF, Wong JS, Deo RC, Schwarz JM, et al. Effects of the Absence of Apolipoprotein E on Lipoproteins, Neurocognitive Function, and Retinal Function. JAMA Neurol. 2014;71(10):1228-36.

31. Rodriguez GA, Burns MP, Weeber EJ, Rebeck GW. Young APOE4 targeted replacement mice exhibit poor spatial learning and memory, with reduced dendritic spine density in the medial entorhinal cortex. Learn Mem. 2013;20:256-66.

32. Salomon-Zimri S, Boehm-Cagan A, Liraz O, Michaelson DM. Hippocampusrelated cognitive impairments in young apoE4 targeted replacement mice. Neurodegener Dis. 2014;13:86-92.

33. Bour A, Grootendorst J, Vogel E, Kelche C, Dodart JC, Bales K, et al. Middleaged human apoE4 targeted-replacement mice show retention deficits on a wide range of spatial memory tasks. Behav Brain Res. 2008;193:174-82.

34. Grootendorst J, Bour A, Vogel E, Kelche C, Sullivan PM, Dodart JC, et al. Human apoE targeted replacement mouse lines: h-apoE4 and h-apoE3 mice 
differ on spatial memory performance and avoidance behavior. Behav Brain Res. 2005;159:1-14.

35. Tai LM, Youmans KL, Jungbauer L, Yu C, Ladu MJ. Introducing Human APOE into Abeta Transgenic Mouse Models. Inter J Alzheimer's Dis. 2011;2011:810981.

36. Raber J, Wong D, Yu GQ, Buttini M, Mahley RW, Pitas RE, et al. Apolipoprotein E and cognitive performance. Nature. 2000;404:352-4.

37. Danysz W, Parsons CG. Alzheimer's disease, beta-amyloid, glutamate, NMDA receptors and memantine-searching for the connections. Br J Pharmacol. 2012;167:324-52

38. Gong Y, Lippa CF. Review: disruption of the postsynaptic density in Alzheimer's disease and other neurodegenerative dementias. Am J Alzheimers Dis Other Demen. 2010;25:547-55.

39. Stranahan AM, Mattson MP. Selective vulnerability of neurons in layer II of the entorhinal cortex during aging and Alzheimer's disease. Neural Plast. 2010;2010:108190.

40. Ly PT, Song W. Loss of activated CaMKIl at the synapse underlies Alzheimer's disease memory loss. J Neurochem. 2011;119:673-5.

41. Saura CA, Valero J. The role of CREB signaling in Alzheimer's disease and other cognitive disorders. Rev Neurosci. 2011;22:153-69.

42. Paramanik V, Thakur MK. Role of CREB signaling in aging brain. Arch Ital Biol. 2013;151:33-42.

43. Kim JH, Roberts DS, Hu Y, Lau GC, Brooks-Kayal AR, Farb DH, et al. Brainderived neurotrophic factor uses CREB and Egr3 to regulate NMDA receptor levels in cortical neurons. J Neurochem. 2012;120:210-9.

44. Yong SM, Lim ML, Low CM, Wong BS. Reduced neuronal signaling in the ageing apolipoprotein-E4 targeted replacement female mice. Sci Rep. 2014;4:6580.

45. Nwabuisi-Heath E, Rebeck GW, Ladu MJ, Yu C. ApoE4 delays dendritic spine formation during neuron development and accelerates loss of mature spines in vitro. ASN Neuro. 2014;6:e00134.

46. Chen Y, Durakoglugil MS, Xian X, Herz J. ApoE4 reduces glutamate receptor function and synaptic plasticity by selectively impairing ApoE receptor recycling. Proc Natl Acad Sci U S A. 2010;107:12011-6.

47. Zhu Y, Nwabuisi-Heath E, Dumanis SB, Tai LM, Yu C, Rebeck GW, et al. APOE genotype alters glial activation and loss of synaptic markers in mice. Glia. 2012;60:559-69.

48. Youmans KL, Tai LM, Nwabuisi-Heath E, Jungbauer L, Kanekiyo T, Gan M, et al. APOE4-specific Changes in Abeta Accumulation in a New Transgenic Mouse Model of Alzheimer Disease. J Biol Chem. 2012;287:41774-86.

49. Dumanis SB, Tesoriero JA, Babus LW, Nguyen MT, Trotter JH, Ladu MJ, et al. ApoE4 decreases spine density and dendritic complexity in cortical neurons in vivo. J Neurosci J Soc Neurosci. 2009;29:15317-22.

50. Trommer BL, Shah C, Yun SH, Gamkrelidze G, Pasternak ES, Ye GL, et al. ApoE isoform affects LTP in human targeted replacement mice. Neuroreport. 2004;15:2655-8.

51. Trommer BL, Shah C, Yun SH, Gamkrelidze G, Pasternak ES, Stine WB, et al. ApoE isoform-specific effects on LTP: blockade by oligomeric amyloid-beta1-42. Neurobiol Dis. 2005;18:75-82.

52. Manelli AM, Bulfinch LC, Sullivan PM, LaDu MJ. Abeta42 neurotoxicity in primary co-cultures: effect of apoE isoform and Abeta conformation. Neurobiol Aging. 2007:28:1139-47.

53. Altmann A, Tian L, Henderson WW, Greicius MD. Sex modifies the APOErelated risk of developing Alzheimer disease. Ann Neurol. 2014;75:563-73.

54. Bretsky PM, Buckwalter JG, Seeman TE, Miller CA, Poirier J, Schellenberg GD, et al. Evidence for an interaction between apolipoprotein E genotype, gender, and Alzheimer disease. Alzheimer Dis Assoc Disord. 1999;13:216-21.

55. Payami H, Zareparsi S, Montee KR, Sexton GJ, Kaye JA, Bird TD, et al. Gender difference in apolipoprotein E-associated risk for familial Alzheimer disease: a possible clue to the higher incidence of Alzheimer disease in women. Am J Hum Genet. 1996;58:803-11.

56. Sullivan PM, Mezdour H, Aratani Y, Knouff C, Najib J, Reddick RL, et al. Targeted replacement of the mouse apolipoprotein $\mathrm{E}$ gene with the common human APOE3 allele enhances diet-induced hypercholesterolemia and atherosclerosis. J Biol Chem. 1997;272:17972-80.

57. Oakley H, Cole SL, Logan S, Maus E, Shao P, Craft J, et al. Intraneuronal beta-amyloid aggregates, neurodegeneration, and neuron loss in transgenic mice with five familial Alzheimer's disease mutations: potential factors in amyloid plaque formation. J Neurosci. 2006;26:10129-40.

58. Tai LM, Koster KP, Luo J, Lee SH, Wang YT, Collins NC, et al. Amyloid-beta Pathology and APOE Genotype Modulate Retinoid X Receptor Agonist Activity in Vivo. J Biol Chem. 2014;289:30538-55.
59. Tai LM, Bilousova T, Jungbauer L, Roeske SK, Youmans KL, Yu C, et al. Levels of soluble apolipoprotein E/amyloid-beta (Abeta) complex are reduced and oligomeric Abeta increased with APOE4 and Alzheimer disease in a transgenic mouse model and human samples. J Biol Chem. 2013;288:5914-26.

60. Sullivan PM, Han B, Liu F, Mace BE, Ervin JF, Wu S, et al. Reduced levels of human apoE4 protein in an animal model of cognitive impairment. Neurobiol Aging. 2011;32:791-801.

61. Cruchaga C, Kauwe JS, Nowotny P, Bales K, Pickering EH, Mayo K, et al. Cerebrospinal fluid APOE levels: an endophenotype for genetic studies for Alzheimer's disease. Hum Mol Genet. 2012;21:4558-71.

62. Riddell DR, Zhou H, Atchison K, Warwick HK, Atkinson PJ, Jefferson J, et al. Impact of apolipoprotein E (ApoE) polymorphism on brain ApoE levels. J Neurosci. 2008;28:11445-53.

63. Vitek MP, Brown CM, Colton CA. APOE genotype-specific differences in the innate immune response. Neurobiol Aging. 2009;30:1350-60.

64. Martinez-Morillo E, Hansson O, Atagi Y, Bu G, Minthon L, Diamandis EP, et al. Total apolipoprotein E levels and specific isoform composition in cerebrospinal fluid and plasma from Alzheimer's di'sease patients and controls. Acta Neuropathol. 2014;127:633-43.

65. May P, Rohlmann A, Bock HH, Zurhove K, Marth JD, Schomburg ED, et al. Neuronal LRP1 functionally associates with postsynaptic proteins and is required for normal motor function in mice. Mol Cell Biol. 2004;24:8872-83.

66. Lin YC, Koleske AJ. Mechanisms of synapse and dendrite maintenance and their disruption in psychiatric and neurodegenerative disorders. Annu Rev Neurosci. 2010;33:349-78

67. Pozueta J, Lefort R, Shelanski ML. Synaptic changes in Alzheimer's disease and its models. Neuroscience. 2013;251:51-65.

68. Sze Cl, Troncoso JC, Kawas C, Mouton P, Price DL, Martin LJ. Loss of the presynaptic vesicle protein synaptophysin in hippocampus correlates with cognitive decline in Alzheimer disease. J Neuropathol Exp Neurol. 1997:56:933-44.

69. Zhang F, Kang Z, Li W, Xiao Z, Zhou X. Roles of brain-derived neurotrophic factor/tropomyosin-related kinase B (BDNF/TrkB) signalling in Alzheimer's disease. J Clin Neurosci. 2012;19:946-9.

70. Pugazhenthi S, Wang M, Pham S, Sze Cl, Eckman CB. Downregulation of CREB expression in Alzheimer's brain and in Abeta-treated rat hippocampal neurons. Mol Neurodegener. 2011;6:60.

71. Ohkubo N, Mitsuda N, Tamatani M, Yamaguchi A, Lee YD, Ogihara T, et al. Apolipoprotein E4 stimulates CREB's transcriptional activity through the ERK pathway. J Biol Chem. 2000;276:3046-53.

72. Garzon DJ, Fahnestock M. Oligomeric amyloid decreases basal levels of brain-derived neurotrophic factor (BDNF) mRNA via specific downregulation of BDNF transcripts IV and V in differentiated human neuroblastoma cells. J Neurosci. 2007:27:2628-35.

73. Min D, Guo F, Zhu S, Xu X, Mao X, Cao Y, et al. The alterations of $\mathrm{Ca} 2+/$ calmodulin/CaMKII/CaV1.2 signaling in experimental models of Alzheimer's disease and vascular dementia. Neurosci Lett. 2013;538:60-5.

74. Kanekiyo T, Xu H, Bu G. ApoE and Abeta in Alzheimer's disease: accidental encounters or partners? Neuron. 2014;81:740-54.

75. Andrews-Zwilling Y, Bien-Ly N, Xu Q, Li G, Bernardo A, Yoon SY, et al. Apolipoprotein E4 causes age- and Tau-dependent impairment of GABAergic interneurons, leading to learning and memory deficits in mice. J Neuorosci. 2010;30:13707-17.

76. Siegel JA, Haley GE, Raber J. Apolipoprotein E isoform-dependent effects on anxiety and cognition in female TR mice. Neurobiol Aging. 2012;33:345-58.

77. Robertson J, Curley J, Kaye J, Quinn J, Pfankuch T, Raber J. apoE isoforms and measures of anxiety in probable AD patients and Apoe-/- mice. Neurobiol Aging. 2005;26:637-43.

78. Ohno M, Chang L, Tseng W, Oakley H, Citron M, Klein WL, et al. Temporal memory deficits in Alzheimer's mouse models: rescue by genetic deletion of BACE1. Eur J Neurosci. 2006;23:251-60.

79. Urano T, Tohda C. Icariin improves memory impairment in Alzheimer's disease model mice (5XFAD) and attenuates amyloid beta-induced neurite atrophy. Phytother Res. 2010;24:1658-63.

80. Shukla V, Zheng YL, Mishra SK, Amin ND, Steiner J, Grant P, et al. A truncated peptide from p35, a Cdk5 activator, prevents Alzheimer's disease phenotypes in model mice. FASEB J. 2013;27:174-86.

81. Tohda C, Urano T, Umezaki M, Nemere I, Kuboyama T. Diosgenin is an exogenous activator of 1,25D(3)-MARRS/Pdia3/ERp57 and improves Alzheimer's disease pathologies in 5XFAD mice. Sci Rep. 2012;2:535. 
82. Devi L, Ohno M. Mitochondrial dysfunction and accumulation of the beta-secretase-cleaved C-terminal fragment of APP in Alzheimer's disease transgenic mice. Neurobiol Dis. 2012;45:417-24.

83. Buttini M, Yu GQ, Shockley K, Huang Y, Jones B, Masliah E, et al. Modulation of Alzheimer-like synaptic and cholinergic deficits in transgenic mice by human apolipoprotein $\mathrm{E}$ depends on isoform, aging, and overexpression of amyloid beta peptides but not on plaque formation. J Neurosci. 2002;22:10539-48.

84. Ji Y, Gong Y, Gan W, Beach T, Holtzman DM, Wisniewski T. Apolipoprotein E isoform-specific regulation of dendritic spine morphology in apolipoprotein E transgenic mice and Alzheimer's disease patients. Neuroscience. 2003;122:305-15.

85. Wang C, Wilson WA, Moore SD, Mace BE, Maeda N, Schmechel DE, et al. Human apoE4-targeted replacement mice display synaptic deficits in the absence of neuropathology. Neurobiol Dis. 2005;18:390-8.

86. Zhong N, Scearce-Levie K, Ramaswamy G, Weisgraber KH. Apolipoprotein E4 domain interaction: synaptic and cognitive deficits in mice. Alzheimer's Dementia J Alzheimer's Assoc. 2008:4:179-92.

87. Sen A, Alkon DL, Nelson TJ. Apolipoprotein E3 (ApoE3) but not ApoE4 protects against synaptic loss through increased expression of protein kinase C epsilon. J Biol Chem. 2012;287:15947-58.

88. Calhoun ME, Kurth D, Phinney AL, Long JM, Hengemihle J, Mouton PR, et al. Hippocampal neuron and synaptophysin-positive bouton number in aging C57BL/6 mice. Neurobiol Aging. 1998;19:599-606.

89. Nicolle MM, Gallagher M, McKinney M. No loss of synaptic proteins in the hippocampus of aged, behaviorally impaired rats. Neurobiol Aging. 1999:20:343-8

90. Lin N, Pan XD, Chen AQ, Zhu YG, Wu M, Zhang J, et al. Tripchlorolide improves age-associated cognitive deficits by reversing hippocampal synaptic plasticity impairment and NMDA receptor dysfunction in SAMP8 mice. Behav Brain Res. 2014;258:8-18.

91. Billard JM, Rouaud E. Deficit of NMDA receptor activation in CA1 hippocampal area of aged rats is rescued by D-cycloserine. Eur J Neurosci. 2007; 25:2260-8.

92. Bodhinathan K, Kumar A, Foster TC. Intracellular redox state alters NMDA receptor response during aging through $\mathrm{Ca} 2+$ /calmodulin-dependent protein kinase II. J Neurosci. 2010;30:1914-24.

93. Cammarota M, Bevilaqua LR, Viola H, Kerr DS, Reichmann B, Teixeira V, et al. Participation of CaMKII in neuronal plasticity and memory formation. Cell Mol Neurobiol. 2002;22:259-67.

94. Miller S, Yasuda M, Coats JK, Jones Y, Martone ME, Mayford M. Disruption of dendritic translation of CaMKIlalpha impairs stabilization of synaptic plasticity and memory consolidation. Neuron. 2002;36:507-19.

95. Fowler SW, Chiang AC, Savjani RR, Larson ME, Sherman MA, Schuler DR, et al. Genetic modulation of soluble abeta rescues cognitive and synaptic impairment in a mouse model of Alzheimer's disease. J Neurosci. 2014;34:7871-85

96. Oike Y, Takakura N, Hata A, Kaname T, Akizuki M, Yamaguchi Y, et al. Mice homozygous for a truncated form of CREB-binding protein exhibit defects in hematopoiesis and vasculo-angiogenesis. Blood. 1999;93:2771-9.

97. Mu JS, Li WP, Yao ZB, Zhou XF. Deprivation of endogenous brain-derived neurotrophic factor results in impairment of spatial learning and memory in adult rats. Brain Res. 1999;835:259-65.

98. Tohda C, Nakada R, Urano T, Okonogi A, Kuboyama T. Kamikihi-to (KKT) rescues axonal and synaptic degeneration associated with memory impairment in a mouse model of Alzheimer's disease, 5XFAD. Int J Neurosci. 2011;121:641-8.

99. Webster SJ, Bachstetter AD, Nelson PT, Schmitt FA, Van Eldik LJ. Using mice to model Alzheimer's dementia: an overview of the clinical disease and the preclinical behavioral changes in 10 mouse models. Front Genet. 2014;5:88.

100. Riedel G, Platt B, Micheau J. Glutamate receptor function in learning and memory. Behav Brain Res. 2003;140:1-47.

101. Verghese PB, Castellano JM, Garai K, Wang Y, Jiang H, Shah A, et al. ApoE influences amyloid-beta (Abeta) clearance despite minimal apoE/Abeta association in physiological conditions. Proc Natl Acad Sci U S A. 2013;110:E1807-16.

102. Garai K, Verghese PB, Baban B, Holtzman DM, Frieden C. The Binding of Apolipoprotein E to Oligomers and Fibrils of Amyloid-beta Alters the Kinetics of Amyloid Aggregation. Biochemistry. 2014;53:6323-31.

103. Pankiewicz JE, Guridi M, Kim J, Asuni AA, Sanchez S, Sullivan PM, et al. Blocking the apoE/Abeta interaction ameliorates Abeta-related pathology in
APOE epsilon2 and epsilon4 targeted replacement Alzheimer model mice. Acta Neuropathol Commun. 2014;2:75.

104. Durakoglugil MS, Chen Y, White CL, Kavalali ET, Herz J. Reelin signaling antagonizes beta-amyloid at the synapse. Proc Natl Acad Sci U S A. 2009;106:15938-43.

105. Belinson H, Kariv-Inbal Z, Kayed R, Masliah E, Michaelson DM. Following activation of the amyloid cascade, apolipoprotein E4 drives the in vivo oligomerization of amyloid-beta resulting in neurodegeneration. J Alzheimers Dis. 2010;22:959-70.

106. Fuentealba RA, Liu Q, Zhang J, Kanekiyo T, Hu X, Lee JM, et al. Low-density lipoprotein receptor-related protein 1 (LRP1) mediates neuronal Abeta42 uptake and lysosomal trafficking. PLoS One. 2010;5:e11884.

107. Kanekiyo T, Cirrito JR, Liu CC, Shinohara M, Li J, Schuler DR, et al. Neuronal Clearance of Amyloid-beta by Endocytic Receptor LRP1. J Neurosci. 2013;33:19276-83.

108. Li J, Kanekiyo T, Shinohara M, Zhang Y, LaDu MJ, Xu H, et al. Differential regulation of amyloid-beta endocytic trafficking and lysosomal degradation by apolipoprotein E isoforms. J Biol Chem. 2012;287:44593-601.

109. Herz J, Chen Y. Reelin, lipoprotein receptors and synaptic plasticity. Nat Rev Neurosci. 2006;7:850-9.

110. Beffert U, Weeber EJ, Durudas A, Qiu S, Masiulis I, Sweatt JD, et al. Modulation of synaptic plasticity and memory by Reelin involves differential splicing of the lipoprotein receptor Apoer2. Neuron. 2005:47:567-79.

111. Chen Y, Beffert U, Ertunc M, Tang TS, Kavalali ET, Bezprozvanny I, et al. Reelin modulates NMDA receptor activity in cortical neurons. J Neurosci. 2005;25:8209-16

112. Heeren J, Grewal T, Laatsch A, Becker N, Rinninger F, Rye KA, et al. Impaired recycling of apolipoprotein E4 is associated with intracellular cholesterol accumulation. J Biol Chem. 2004;279:55483-92.

113. Wolf AB, Valla J, Bu G, Kim J, Ladu MJ, Reiman EM, et al. Apolipoprotein E as a beta-amyloid-independent factor in alzheimer's disease. Alzheimer's Res Ther. 2013;5:38.

114. Haass C, Selkoe DJ. Soluble protein oligomers in neurodegeneration: lessons from the Alzheimer's amyloid beta-peptide. Nat Rev Mol Cell Biol. 2007;8:101-12.

115. Rodriguez GA, Tai LM, LaDu MJ, Rebeck GW. Human APOE4 increases microglia reactivity at Abeta plaques in a mouse model of Abeta deposition. J Neuroinflammation. 2014;11:111.

116. Kunzler J, Youmans KL, Yu C, Ladu MJ, Tai L. APOE modulates the effect of estrogen therapy on Abeta accumulation EFAD-Tg mice. Neurosci Lett. 2013;560:131-6.

117. Tai LM, Mehra S, Shete V, Estus S, Rebeck GW, Bu G, et al. Soluble apoE/ Abeta complex: mechanism and therapeutic target for APOE4-induced AD risk. Mol Neurodegener. 2014;9:2.

118. Bales KR, Verina T, Cummins DJ, Du Y, Dodel RC, Saura J, et al. Apolipoprotein $\mathrm{E}$ is essential for amyloid deposition in the APP(V717F) transgenic mouse model of Alzheimer's disease. Proc Natl Acad Sci U S A. 1999;96:15233-8.

119. Holtzman DM, Bales KR, Wu S, Bhat P, Parsadanian M, Fagan AM, et al. Expression of human apolipoprotein $\mathrm{E}$ reduces amyloid-beta deposition in a mouse model of Alzheimer's disease. J Clin Invest. 1999;103:R15-21.

120. Holtzman DM, Bales KR, Tenkova T, Fagan AM, Parsadanian M, Sartorius LJ, et al. Apolipoprotein $\mathrm{E}$ isoform-dependent amyloid deposition and neuritic degeneration in a mouse model of Alzheimer's disease. Proc Natl Acad Sci U S A. 2000;97:2892-7.

121. Boehm-Cagan A, Michaelson DM. Reversal of apoE4-Driven Brain Pathology and Behavioral Deficits by Bexarotene. J Neurosci. 2014;34:7293-301.

122. Bell RD, Winkler EA, Singh I, Sagare AP, Deane R, Wu Z, et al. Apolipoprotein E controls cerebrovascular integrity via cyclophilin A. Nature. 2012;485:512-6.

123. Bachmeier C, Paris D, Beaulieu-Abdelahad D, Mouzon B, Mullan M, Crawford F. A multifaceted role for apoE in the clearance of beta-amyloid across the blood-brain barrier. Neurodegener Dis. 2013;11:13-21.

124. Hartman RE, Wozniak DF, Nardi A, Olney JW, Sartorius L, Holtzman DM. Behavioral phenotyping of GFAP-apoE3 and -apoE4 transgenic mice: apoE4 mice show profound working memory impairments in the absence of Alzheimer's-like neuropathology. Exp Neurol. 2001;170:326-44.

125. van Meer $\mathrm{P}$, Acevedo S, Raber J. Impairments in spatial memory retention of GFAP-apoE4 female mice. Behav Brain Res. 2007;176:372-5.

126. Raber J, Wong D, Buttini M, Orth M, Bellosta S, Pitas RE, et al. Isoformspecific effects of human apolipoprotein $E$ on brain function revealed in ApoE knockout mice: increased susceptibility of females. Proc Natl Acad Sci U S A. 1998;95:10914-9. 
127. Zepa L, Frenkel M, Belinson H, Kariv-Inbal Z, Kayed R, Masliah E, et al. ApoE4-Driven Accumulation of Intraneuronal Oligomerized Abeta42 following Activation of the Amyloid Cascade In Vivo Is Mediated by a Gain of Function. Inter J Alzheimer's Dis. 2011;2011:792070.

128. Bien-Ly N, Andrews-Zwilling Y, Xu Q, Bernardo A, Wang C, Huang Y. C-terminal-truncated apolipoprotein (apo) E4 inefficiently clears amyloid\{beta\} (A\{beta\}) and acts in concert with A\{beta\} to elicit neuronal and behavioral deficits in mice. Proc Natl Acad Sci U S A. 2011;108:4236-41.

129. Rohn TT. Proteolytic cleavage of apolipoprotein E4 as the keystone for the heightened risk associated with Alzheimer's disease. Int J Mol Sci. 2013;14:14908-22

130. Hussain A, Luong M, Pooley A, Nathan BP. Isoform-specific effects of apoE on neurite outgrowth in olfactory epithelium culture. J Biomed Sci. 2013;20:49.

131. Nathan BP, Jiang Y, Wong GK, Shen F, Brewer GJ, Struble RG. Apolipoprotein E4 inhibits, and apolipoprotein E3 promotes neurite outgrowth in cultured adult mouse cortical neurons through the low- density lipoprotein receptor-related protein. Brain Res. 2002;928:96-105.

132. Shi YQ, Huang TW, Chen LM, Pan XD, Zhang J, Zhu YG, et al. Ginsenoside Rg1 attenuates amyloid-beta content, regulates PKA/CREB activity, and improves cognitive performance in SAMP8 mice. J Alzheimers Dis. 2010;19:977-89.

133. Youmans KL, Leung S, Zhang J, Maus E, Baysac K, Bu G, et al. Amyloidbeta42 alters apolipoprotein $\mathrm{E}$ solubility in brains of mice with five familial AD mutations. J Neurosci Methods. 2011;196:51-9.

\section{Submit your next manuscript to BioMed Central and take full advantage of:}

- Convenient online submission

- Thorough peer review

- No space constraints or color figure charges

- Immediate publication on acceptance

- Inclusion in PubMed, CAS, Scopus and Google Scholar

- Research which is freely available for redistribution 